\title{
Differences in nano-topography and tribochemistry of ZDDP tribofilms from variations in contact configuration with steel and DLC surfaces
}

\author{
Lucija ČOGA ${ }^{1}$, Somayeh AKBARI ${ }^{2}$, Janez KOVAČ $\check{\check{C}}^{3}$, Mitjan KALIN ${ }^{1, *}$ \\ ${ }^{1}$ Laboratory for Tribology and Interface Nanotechnology, Faculty of Mechanical Engineering, University of Ljubljana, Ljubljana 1000, \\ Slovenia \\ ${ }^{2}$ NanoSciTec GmbH, Munich 80687, Germany \\ ${ }^{3}$ Department of Surface Engineering and Optoelectronics, Jožef Stefan Institute, Ljubljana 1000, Slovenia \\ Received: 27 May 2020 / Revised: 03 November 2020 / Accepted: 11 January 2021 \\ (C) The author(s) 2021.
}

\begin{abstract}
In this work, we evaluated the effect of the counter-body material (the same or dissimilar) and contact configuration (moving or stationary body), at similar contact tribological conditions, on the tribochemical and nanotopography characteristics of adsorbed surface films. Zinc dialkyldithiophosphate (ZDDP), the best performing anti-wear additive, was used in self-mated steel/steel and DLC/DLC contacts, which were compared with mixed steel/DLC and DLC/steel contacts in 1-h and 6-h sliding tests. The macroscale (tribometer) and nanoscale (atomic force microscopy) friction, thickness, topography, and chemical (attenuated total reflectionFourier transform infrared spectroscopy and X-ray photoelectron spectroscopy) properties of the tribofilms were studied. The results revealed unexpectedly large differences in all the studied tribofilm parameters; this is because all the tribofilms are completely different; this includes the chemical composition, which is known to have a crucial effect on the nano- and macro-scale tribological properties. These results clearly demonstrate that the surface material, additives, and common contact operating parameters, that is, pressure, velocity, and temperature, crucially affect the ZDDP tribofilm as well as the position of the moving or stationary surface within the contact, and the material of the moving/stationary bodies.
\end{abstract}

Keywords: dithiophosphate (ZDDP); diamond-like carbon (DLC); steel; tribofilm; tribochemistry; nano-friction; thickness; topography

\section{Introduction}

Diamond-like carbon (DLC) coatings possess superior properties such as chemical inertness and high hardness, which result in superior tribological properties [1-3]. This makes them an excellent material for application in the most demanding contact conditions, typically in dry or boundary lubricated conditions, where low friction and durability are crucial. Automotive applications are paramount examples of this. However, prior to the introduction of DLC coatings in automotive applications, it is necessary for them to be tailored and adapted to conventionally formulated lubricants. Among the many additives in automotive lubricants, zinc dialkyldithiophosphates (ZDDPs) are one of the most significant one, providing low wear and durability of the engine components.

Accordingly, ZDDPs are some of the best-performing, and therefore, most extensively studied additives for automotive applications [4]. Many studies have evaluated the interactions between DLC coatings and lubricants that contain ZDDP [5-12]. Despite this, the

* Corresponding author: Mitjan KALIN, E-mail: mitjan.kalin@tint.fs.uni-lj.si 
lubrication mechanism of DLC with the ZDDP additive is still not well understood. Furthermore, because of the ever-more-stringent environmental restrictions, there is a requirement to replace the ZDDP in lubricants with alternatives [13]; therefore, understanding ZDDPbased DLC lubrication mechanisms is urgent.

For metallic surfaces such as steel, it is well known that under sliding conditions, ZDDP forms thick, pad structures of gradually structured layers: a zinc polyphosphate layer in the upper part, and iron and zinc thio(phosphate) at the lower part [14-17]. The formation of this tribochemical film increases the surface roughness, and consequently, the coefficient of friction (COF) when compared to base oils [4, 18, 19]. However, on significantly less reactive DLC surfaces, ZDDP forms weakly adhered boundary films. Based on previous reports [5-7], the properties and tribochemistry of these films vary considerably and are considerably less clear than those of steel surfaces. One reason for this may be the many types of DLC coatings, with only variations in the $\mathrm{C}$ or $\mathrm{H}$ contents, and even more when doped, for example, with $\mathrm{Si}, \mathrm{Ti}$, and W/WC, where the properties of the ZDDP tribofilm could vary and affect these surface properties, as previously reported by Refs. [5-11, 20-23]. Moreover, in some studies, ZDDP tribochemical films were detected on DLC coatings [5-10, 24, 25], whereas no tribofilm was observed in some other cases [20,26].

No study has evaluated the contact configuration, that is, the change of the tribofilms, their properties, and tribochemistry, when in dissimilar-material contacts different materials, are set as stationary or moving bodies. In this study, we evaluate the contacting surfaces as they are exposed to tribological contact for different time, which affects their interfacial temperature, shearing conditions, formation of the tribofilm, and overall tribological behavior. This phenomenon was found to be very pronounced for polymers, for example, polyamide in mixed contacts with steel [27].

It is also unclear how the tribofilms in self-mated steel or DLC contacts differ from the tribofilms in dissimilar contacts of steel and DLC. It is known that in DLC/DLC contacts, the tribofilms are very limited, poor, or even do not exist, whereas when DLC is in contact with steel, these films are more obvious and easier to observe [5-12, 20, 21, 24, 25, 28-30].
Nevertheless, a systematic and comprehensive evaluation of the effect of the counter body and contact configuration on the ZDDP-based DLC tribofilm formation, that is, whether DLC or steel is moving or stationary in contact, has not been reported.

In this study, we evaluate the influence of various contact configurations with hydrogenated DLC coating and steel that were lubricated with ZDDP-additivated oil on the nanoscale friction, tribofilm properties (thickness, topography, and chemical structure) and, in turn, the overall macroscale tribological behavior of the evaluated contacts. For this purpose, four contact configurations were studied: steel/steel, DLC/DLC, DLC/steel, and steel/DLC. After 1-h and 6-h sliding tests that also reveal the changes during the tribofilm's development over time, both contacting surfaces were analyzed by atomic force microscopy (AFM) and scanning white-light interferometry (SWLI) to determine the total tribofilm thickness and morphology, whereas attenuated total reflection-Fourier transform infrared (ATR-FTIR) spectroscopy and X-ray photoelectron spectroscopy (XPS) were employed to evaluate the tribofilm's chemical structure.

\section{Experimental}

\subsection{Materials}

Standard discs from AISI 52100/100Cr6 bearing steel $(\Phi=24 \mathrm{~mm})$ with a hardness of $850 \mathrm{HV}$ and $\mathrm{Ra}$ roughness of $0.01 \mu \mathrm{m}$ were prepared by polishing and grinding using differently graded sandpapers and abrasive discs. Balls from the same material with diameters of $10 \mathrm{~mm}$ were used as purchased, without any mechanical treatment. Some of these samples were coated with an approximately $1-\mu \mathrm{m}$-thick amorphous and hydrogenated DLC coating, with $\mathrm{sp}^{3} /\left(\mathrm{sp}^{3}+\mathrm{sp}^{2}\right)$ ratio of $35 \%-40 \%$. The hydrogen content was $30 \%$. The coating is hereinafter referred to as the DLC coating. The coating adhesion was improved by two interlayers, namely the Ti- and Si-based interlayers. The DLC coating was deposited using plasma-assisted CVD from Oerlikon Balzers, Limoges, France. The hydrogenated DLC coating was selected because some of the previous studies showed that it possesses very good tribological behavior, better than 
doped coatings [31]. After the coating deposition, the surface roughness did not change by any notable extent compared to the initial values of the steel samples. The measured characteristics of the coated surfaces and substrates are listed in Table 1.

We used a primary zinc dialkyldithiophosphate, commercially available from Lubrizol (Derby, UK) and $1 \mathrm{wt} \%$ solution of ZDDP in Group IV synthetic oil, PAO6.

\subsection{Tribological tests}

The tribological tests were performed on a CETR UMT II tribometer (now Bruker, USA) with a stationary ball on a moving disc with reciprocating geometry (hereinafter referred to as the stationary and moving bodies), as shown in Fig. 1. Four different contact configurations were evaluated: DLC/DLC, steel/steel, stationary DLC against moving steel (denoted DLC/ steel contact), and stationary steel against moving DLC (denoted steel/DLC contact). The tests were performed at $100{ }^{\circ} \mathrm{C}$ and a normal load $\left(F_{\mathrm{N}}\right)$ of $10 \mathrm{~N}$ corresponding

Table 1 Surface roughness of bare steel surfaces and those coated with DLC.

\begin{tabular}{|c|c|c|c|c|}
\hline \multirow{2}{*}{ Parameter } & \multicolumn{2}{|c|}{ Steel } & \multicolumn{2}{|c|}{ DLC } \\
\hline & Disc & Ball & Disc & Ball \\
\hline $\begin{array}{l}\text { Roughness, } R a \\
(\mathrm{~nm})\end{array}$ & $5.1 \pm 1.3$ & $13.8 \pm 0.4$ & $6.8 \pm 1.2$ & $11.6 \pm 1.5$ \\
\hline Hardness (GPa) & \multicolumn{2}{|c|}{8.3} & \multicolumn{2}{|c|}{25 [29] } \\
\hline $\begin{array}{l}\text { Thermal } \\
\text { conductivity } \\
(\mathrm{W} /(\mathrm{m} \cdot \mathrm{K}))\end{array}$ & \multicolumn{2}{|r|}{59} & \multicolumn{2}{|c|}{$1-2$} \\
\hline $\begin{array}{l}\text { Specific heat } \\
(\mathrm{J} /(\mathrm{kg} \cdot \mathrm{K}))\end{array}$ & \multicolumn{2}{|c|}{460} & \multicolumn{2}{|c|}{970} \\
\hline Density $\left(\mathrm{kg} / \mathrm{m}^{3}\right)$ & \multicolumn{2}{|c|}{7,850} & \multicolumn{2}{|c|}{2,340} \\
\hline
\end{tabular}

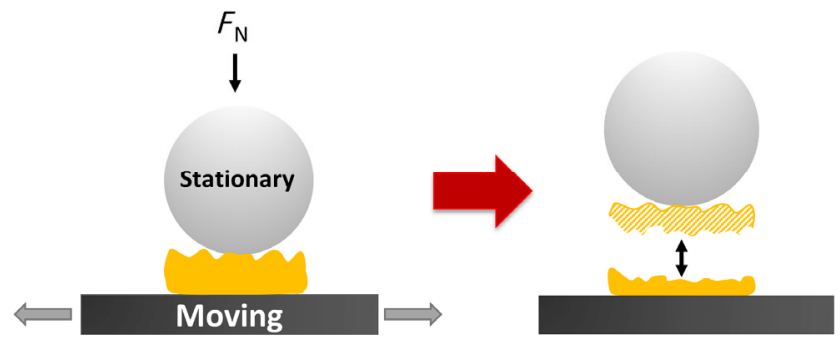

Fig. 1 Schematic of ZDDP tribofilm formation during tribological test with reciprocating geometry using a stationary ball on a moving disc. The tests were performed at $100{ }^{\circ} \mathrm{C}$ and a normal $\operatorname{load}\left(F_{\mathrm{N}}\right)$ of $10 \mathrm{~N}$. to $1 \mathrm{GPa}$ of Hertzian maximum pressure. To evaluate the time evolution of the ZDDP tribofilm, two different sliding time were used: 1 and $6 \mathrm{~h}$, which correspond to 36,000 and 216,000 cycles, and sliding distances of 360 and 2,160 m, respectively. The average sliding velocity in the contact was $0.1 \mathrm{~m} / \mathrm{s}$, which ensured the boundary lubrication conditions, according to the lambda value of 0.08 .

The characteristic COF for each contact configuration was determined as the average COF when the steadystate sliding condition was reached. Each test was repeated at least three times to obtain statistically relevant results, and the mean value of the repeated experiments with \pm one standard deviation of the mean value was reported.

\subsection{Tribofilm analysis}

After the sliding tests, all the specimens were carefully rinsed using n-heptane to remove the excess lubricant before analysis. Two series of tribological samples for each contact configuration were prepared. The first series was used to analyze the surface topography, lateral force mapping (LFM), surface coverage, and tribofilm thickness using AFM. After the AFM analyses, the tribofilm was removed by an EDTA disodium salt solution to determine the wear of the moving surfaces by SWLI and optical microscopy. The second series of the tribological samples was chemically analyzed by ATR-FTIR and XPS.

\subsubsection{AFM}

The topographical and lateral force analyses of both surfaces in contact were performed in contact mode using a commercial atomic force microscope (CP-II, Bruker, USA). Silicon cantilevers with a thickness of $3 \mu \mathrm{m}$ and a spring constant of $0.9 \mathrm{~N} / \mathrm{m}$ were used. The radius of the tip was $9 \mathrm{~nm}$, to a maximum of $12 \mathrm{~nm}$.

The scan rate was in the range of $0.5-1.5 \mathrm{~s}^{-1}$, which varied with the scan size. Topographic and LFM images with scan sizes of $5 \mu \mathrm{m} \times 5 \mu \mathrm{m}$ and $10 \mu \mathrm{m} \times$ $10 \mu \mathrm{m}$ were obtained. Larger scan sizes (i.e., $20 \mu \mathrm{m} \times$ $20 \mu \mathrm{m}$ and $50 \mu \mathrm{m} \times 50 \mu \mathrm{m}$ ) were also used to determine the surface coverage and roughness. Topographic and LFM images inside and outside the wear track were obtained by analyzing at least four different locations, which helped obtain statistically representative 
results. The topographic images were analyzed using AFM ProScan1.9 image-analyzing software.

The tribofilm regions were determined by comparing the topographic images with those of the lateral force. The latter provides information regarding the variation in the frictional force on the sample surface owing to surface inhomogeneity, which enabled us to distinguish the tribofilm regions from those of the bare substrate. The darker LFM image contrast indicates lower friction.

The thickness was determined using a vertical crosssection analysis along several selected lines, where several vertical differences between the substrate's and tribofilm's region were measured, as shown in Fig. 2. The mean values of the measured tribofilm thickness with \pm one standard deviation of the mean value for each contact configuration are reported.

The surface coverage (SC) was determined from the topographic (height) images as follows:

$$
S C=\frac{A_{\mathrm{T}}}{A} \cdot 100 \%
$$

where $A_{\mathrm{T}}$ is the projected surface area of the tribofilm and $A$ is the entire scanned area. $A_{\mathrm{T}}$ was measured using ProScan1.9 Data Acquisition image-analyzing software, where the tribofilm's regions were determined by a function of excluding the height with the help of a histogram. Further, a comparison of the topographic images with the LFM images was used to effectively distinguish the tribofilm's regions from those of the substrate.

\subsubsection{SWLI}

After the AFM analyses, the tribofilm was locally removed from the wear track on the moving surfaces for all the four contacts to measure the wear of the moving surfaces. According to a procedure described in Ref. [32], a single droplet of 0.1-M EDTA disodium salt, mixed in distilled water, was placed on the wear track for a maximum of $3 \mathrm{~min}$ and then wiped off with a tissue paper. The wear was measured using an SWLI microscope (ContourGT-K0, CA, USA) in the vertical-scanning-interferometry mode.

\subsubsection{ATR-FTIR}

The IR spectra were obtained using an ATR-FTIR spectrometer from Perkin Elmer with a diamond ATR, at an incidence angle of $45^{\circ}$. The penetration depth of the IR radiation was approximately $1 \mu \mathrm{m}$, which provides information on the average molecular structure over the entire depth of the tribofilm. The spectra were obtained in the wavelength range of $4,000-450 \mathrm{~cm}^{-1}$. The $1,800-2,500 \mathrm{~cm}^{-1}$ region is not shown because it is a result of the crystal noise. Additionally, 54 scans at a resolution of $4 \mathrm{~cm}^{-1}$ were collected for all the spectra. Prior to the test, the crystal was cleaned with deionized water and dried with a clean cloth. Before measuring the spectrum of the evaluated surface, the background was acquired with the crystal without the sample to ensure that no traces of the solvent remained on the surface of the crystal. The spectrum of the bare surface (steel or DLC) was subtracted from the spectrum of the surface after sliding, to ensure that only the peaks from the tribofilm were present.

\subsubsection{XPS}

In contrast to FTIR, which penetrates the film, XPS has a better surface sensitivity and gives the composition results of approximately $5 \mathrm{~nm}$ of the
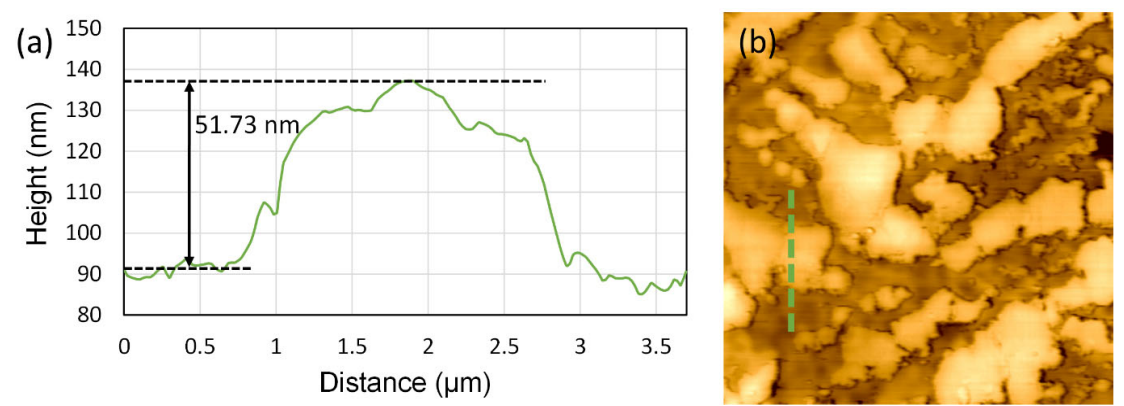

Fig. 2 (a) Cross-section analysis along the selected line indicated on (b) the topographic image. The vertical difference between the substrate and tribofilm region is also indicated. 
tribofilm from the outer surface. The XPS measurements are thus complementary to the FTIR results for the penetration depth. The XPS measurements were performed using a PHI-TFA XPS spectrometer (Physical Electronics, USA) equipped with an Al-monochromatic $X$-ray source and a 16-channel hemispherical electron energy analyzer. Two types of spectra were measured on the analyzed samples: the wide energy range spectra for the quantification of the surface composition, and the high energy resolution spectra for the identification of the chemical bonds. The latter were obtained with an energy resolution of $0.6 \mathrm{eV}$ measured on the Ag $3 d_{5 / 2}$ spectrum. Owing to possible charging of the analyzed surface, the XPS spectra were aligned on the energy scale to the $\mathrm{C} 1 \mathrm{~s}$ peak at $284.8 \mathrm{eV}$ originating from the $\mathrm{C}-\mathrm{C} / \mathrm{C}-\mathrm{H}$ bonds. The XPS spectra were measured outside and inside the wear tracks. The photoelectrons emitted from the surface were collected at an emission angle of $45^{\circ}$ with respect to the sample surface. High energy resolution spectra were deconvoluted using the combined Gaussian (80\%-95\%)/Lorentzian (20\%-5\%) model curves using the Multipak software program.

\section{Results}

\subsection{Tribological tests}

Figure 3(a) shows the characteristic COF after 1-h sliding for all the four contact configurations in the base oil and in the presence of the ZDDP solution. It can be observed that ZDDP affects the friction behavior of the four contacts differently. The highest COF was obtained in the case of steel/steel, followed by the steel/DLC, and then the DLC/steel and DLC/DLC contacts, for which the two COFs were practically the same.

After 6-h sliding, the COF variation between the evaluated contacts increased as the films became steadier (Fig. 3(b)). For the steel/steel, DLC/ steel, and steel/DLC contacts, the COF increased by approximately $25 \%, 2 \%$, and $24 \%$, respectively, whereas it decreased for the DLC/DLC contact by approximately $20 \%$. The different friction behavior of the DLC/DLC contact could be attributed to the absence of steel material. Namely, DLC/DLC is the only contact that exhibits opposite behavior, that is, the reduction of friction,
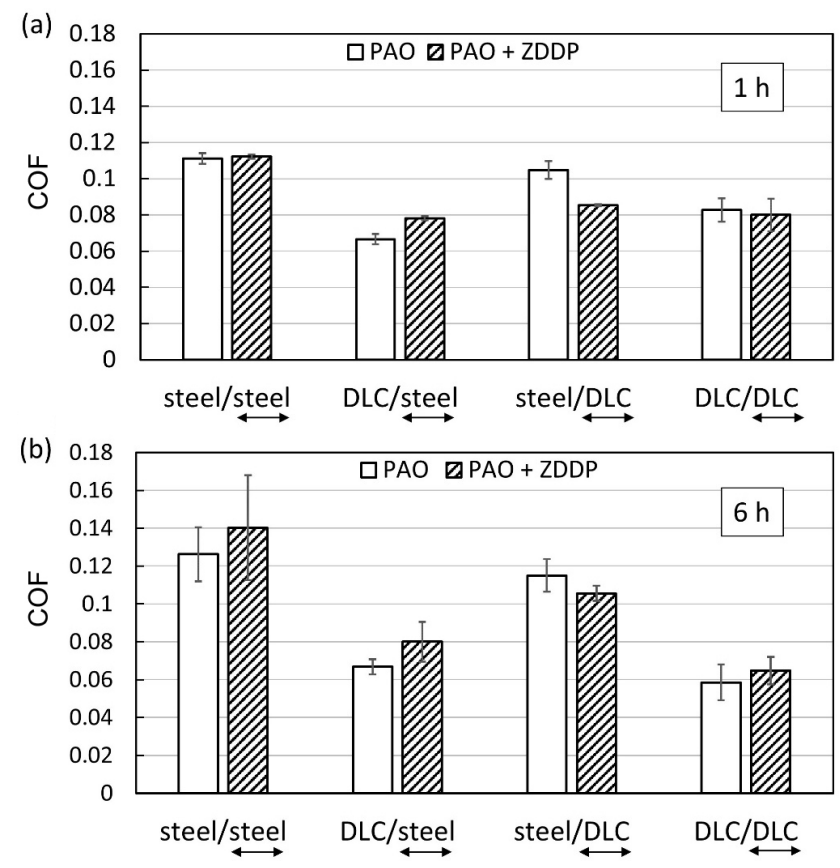

Fig. 3 COF for all four contact configurations in base oil and solution of ZDDP after (a) 1-h and (b) 6-h sliding. Arrows indicate the moving surface.

compared to the increase in friction in the other three contacts with at least one steel surface. This can be because of the lower reactivity and adhesion of lubricants to DLC compared to steel, which is observed in most of the literature.

A remarkable observation drawn from the tribological tests is the different friction behaviors of the mixed contacts, that is, the DLC/steel and steel/DLC contacts. First, the contacts differ in terms of the magnitude of the COF, which is lower for the DLC/steel contact, by approximately $3 \%$ after the 1 -h test and by as much as $25 \%$ after the 6 -h test. Second, the DLC/steel contact exhibits a higher COF with ZDDP than with the base oil, similar to the two self-mated contacts, namely steel/steel and DLC/DLC. In contrast, for the steel/DLC contact, the COF is lower with the ZDDP than with the base oil, regardless of the sliding time.

\subsection{Tribofilm thickness}

Figure 4(a) shows the mean value of the tribofilm thickness on static, moving, and both (total) contacting surfaces for all the four contact configurations after 1-h sliding. In the case of steel/steel, the tribofilm's total thickness was approximately $170 \mathrm{~nm}$. It is worth noting that the tribofilm's thickness on the stationary 


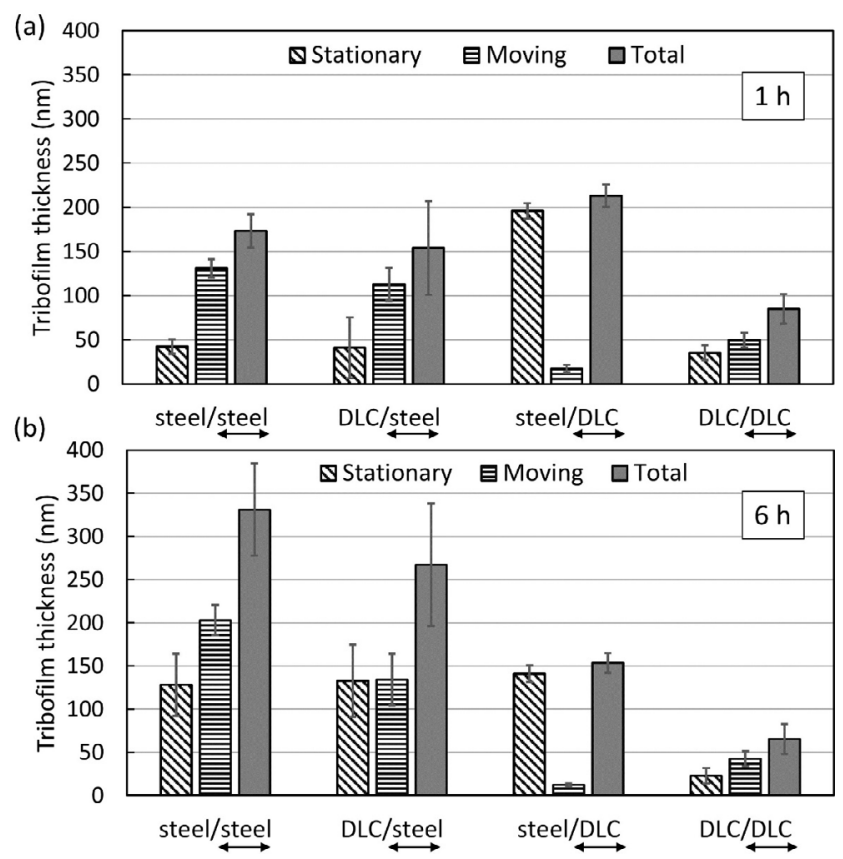

Fig. 4 Mean tribofilm thickness for all four contact configurations after (a) 1-h sliding and (b) 6-h sliding.

surface was considerably lower than that on the moving surface, approximately $40 \mathrm{~nm}$ vs. $130 \mathrm{~nm}$. For the DLC/steel contact, the stationary DLC surface had a smaller tribofilm thickness than the moving steel surface, and was very similar at $40 \mathrm{~nm}$. This resulted in a smaller total tribofilm thickness than in the steel/steel contact, which was approximately $150 \mathrm{~nm}$. This difference can be attributed to the presence of DLC in the contact, which has a considerably lower surface reactivity than steel. Although there was a similar thickness of approximately $50 \mathrm{~nm}$ on the DLC surface, this could indicate some overall changes in the properties of the tribofilm. The third contact, steel/ DLC, in which stationary steel was used against the less-reactive moving DLC surface, resulted in a very thick film of approximately $195 \mathrm{~nm}$ on the stationary steel surface and a very thin film on the moving DLC, of approximately $15 \mathrm{~nm}$. The measured total tribofilm thickness was even higher than that in the steel/steel contact $(210 \mathrm{~nm})$. Finally, in the case of the DLC/DLC contact, the total tribofilm thickness was the lowest among the studied contact configurations, at approximately $85 \mathrm{~nm}$; this was probably because of the low reactivity of both contacting surfaces. The measured tribofilm thickness was approximately 35 and $50 \mathrm{~nm}$ for the stationary and moving bodies, respectively. Therefore, similar to the steel/steel and DLC/steel contacts, the tribofilm thickness on the moving surface was higher than that on the stationary one.

After 6-h sliding (Fig. 4(b)), it was observed that for the contacts in which steel was used as a moving surface (steel/steel and DLC/steel), the tribofilm thickness on both contacting surfaces increased in comparison to the case of the 1-h tests. In the steel/ steel contact, the total tribofilm thickness increased to approximately $330 \mathrm{~nm}$, that is, by approximately $94 \%$, whereas in the DLC/steel contact, it increased to approximately $270 \mathrm{~nm}$, that is, by approximately $80 \%$. However, in the contacts in which the DLC was used as a moving surface (steel/DLC and DLC/DLC contacts), the tribofilm thickness on both contacting surfaces decreased in comparison to the case of the 1-h tests. For the steel/DLC contact, the total tribofilm thickness decreased to approximately $150 \mathrm{~nm}$ (by approximately $30 \%$ ) and for the DLC/DLC contact to approximately $65 \mathrm{~nm}$ (by approximately 24\%).

Additionally, it was observed that the stationary body possesses a smaller thickness than the moving one, which is true for the $1-\mathrm{h}$ and $6-\mathrm{h}$ sliding experiments. The only exception is the steel/DLC contact.

Figure 5 shows the optical images of the wear tracks on the moving surfaces for all the four contact configurations after the tribofilm removal with the chelating agent disodium salt of EDTA. The measured height profiles across the cleaned region of the worn and unworn surfaces are also presented below the optical images.

It is clear that the tribofilm was completely removed from the wear trace on the DLC surfaces, irrespective of the contact configuration. In contrast, for the steel surfaces, dark regions, corresponding to the tribofilm, remained on the surfaces after cleaning. This indicates that the interactions between the surface and ZDDP additive are considerably weaker for the DLC coating. However, the height profiles show that in the case of all the contacts, and the wear was within the range of the surface roughness.

\subsection{Surface topography and lateral force (nano friction) mapping}

Figure 6 shows the topographic images of the 

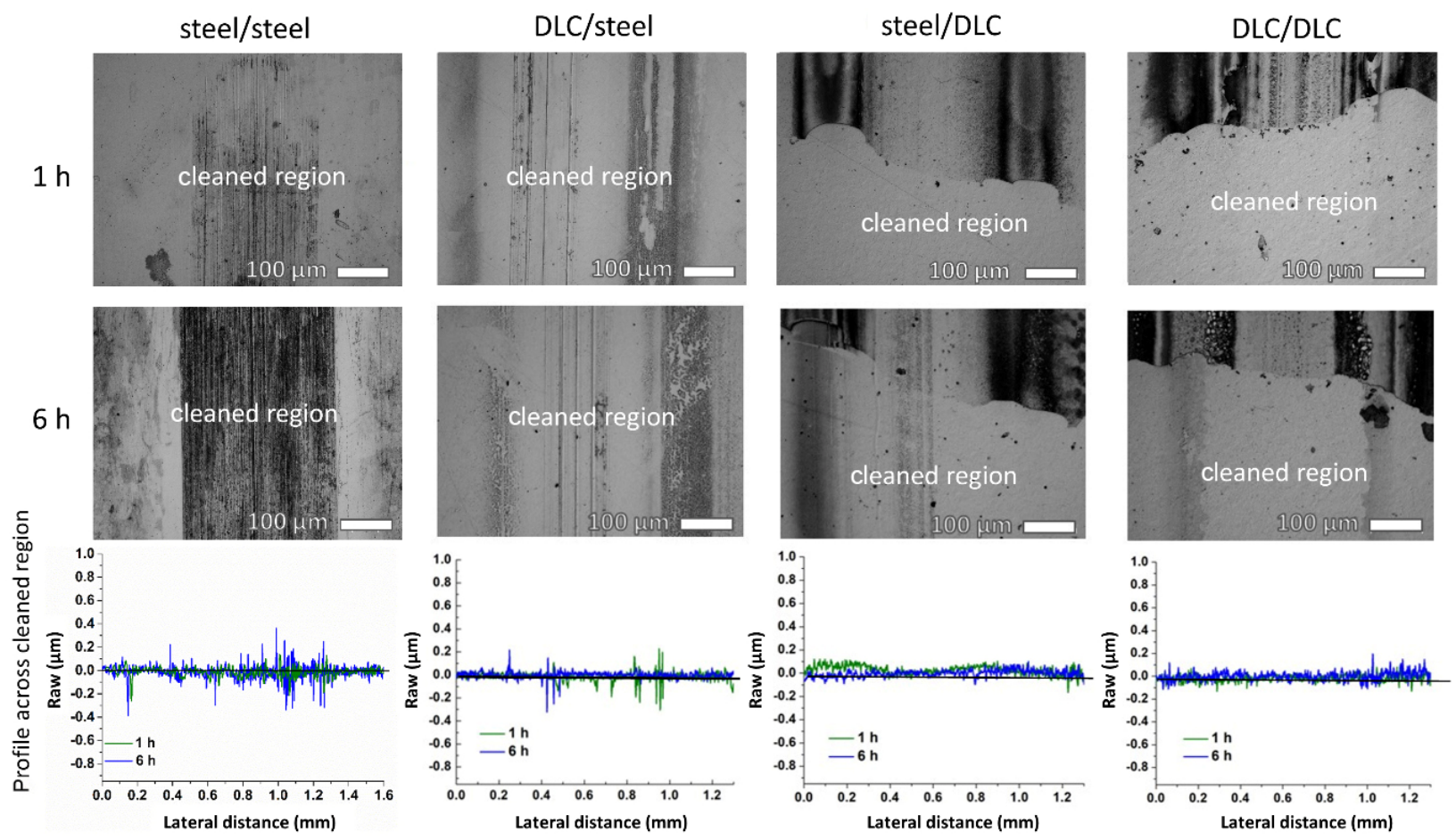

Fig. 5 Optical images of wear tracks on moving surfaces for all four contact configurations after cleaning with EDTA disodium salt solution. Profiles below the images were measured using scanning white-light interferometry across the cleaned region of the wear track.

stationary and moving surfaces before the tribological tests. The polishing marks are clearly visible on all the surfaces.

Figure 7 shows the topographic and corresponding LFM images for the steel/steel contact configuration after 1-h and 6-h sliding experiments. It is evident

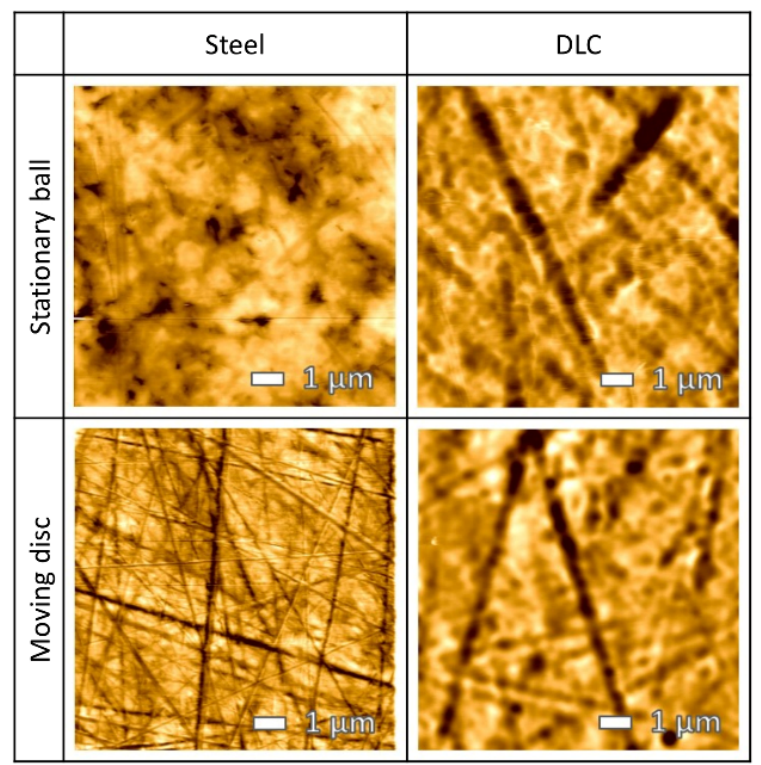

Fig. 6 Topographic images of steel and DLC without any lubricating film. that after 1-h sliding, both the stationary and moving surfaces were completely covered with several layers of the tribofilm. The tribofilm's structure is uniform along all the layers on both contacting surfaces; this is observed from the absence of the LFM contrast between the individual layers. The brighter contrast observed at the edges of the layers/islands in the LFM signal is attributed to variations in the surface topography. By increasing the sliding time to $6 \mathrm{~h}$, the tribofilm disintegrated into smaller islands of different shapes (a pad-like structure) on both the stationary and moving surfaces. Such evolution of the film morphology with the sliding time may result from a combination of mechanical action and changes in the composition of the oil solution owing to thermooxidative decomposition [15].

In the DLC/steel contact (Fig. 8), the stationary DLC surface was only partially covered with unevenly distributed, elongated islands of the ZDDP tribofilm after 1-h sliding. As the sliding time increased to $6 \mathrm{~h}$, larger inhomogeneous patches were observed, with the surface coverage increasing from approximately $22 \%$ after 1 -h sliding to $58 \%$ after $6 \mathrm{~h}$. In contrast, the surface of the moving steel body was 


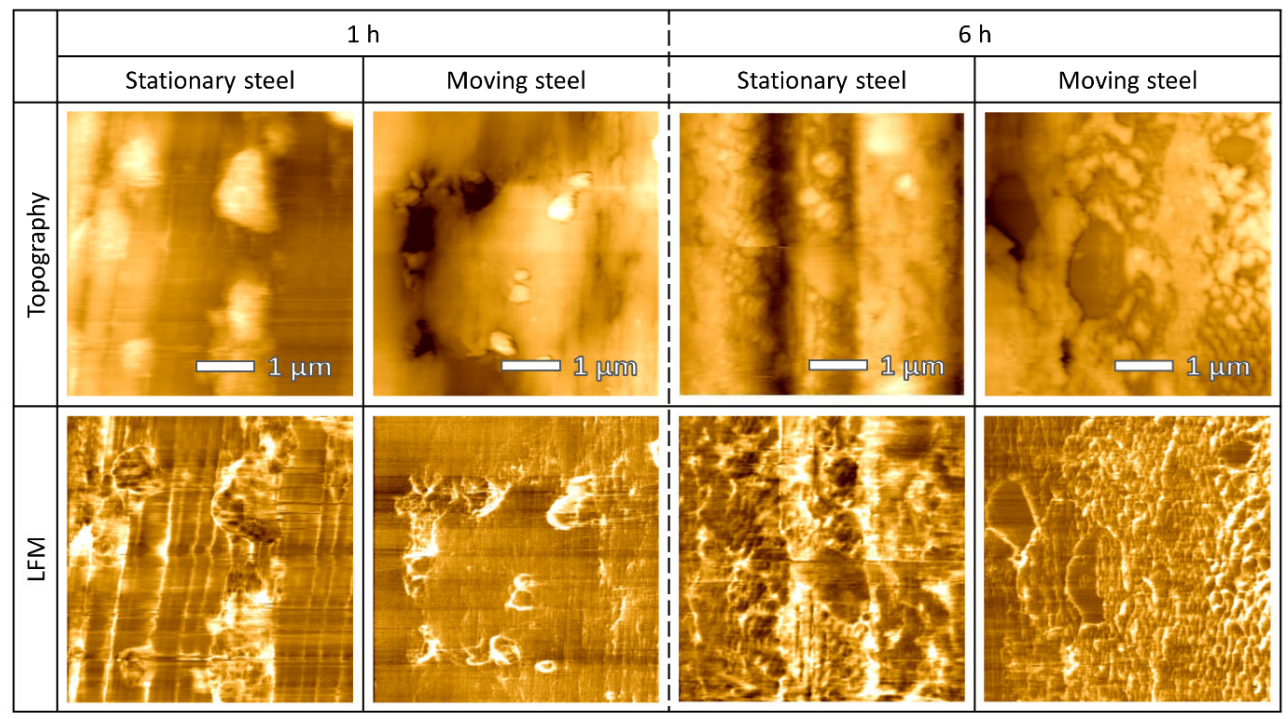

Fig. 7 Topographic and corresponding LFM images of stationary steel and moving steel surfaces for the steel/steel contact configuration after 1-h and 6-h sliding.

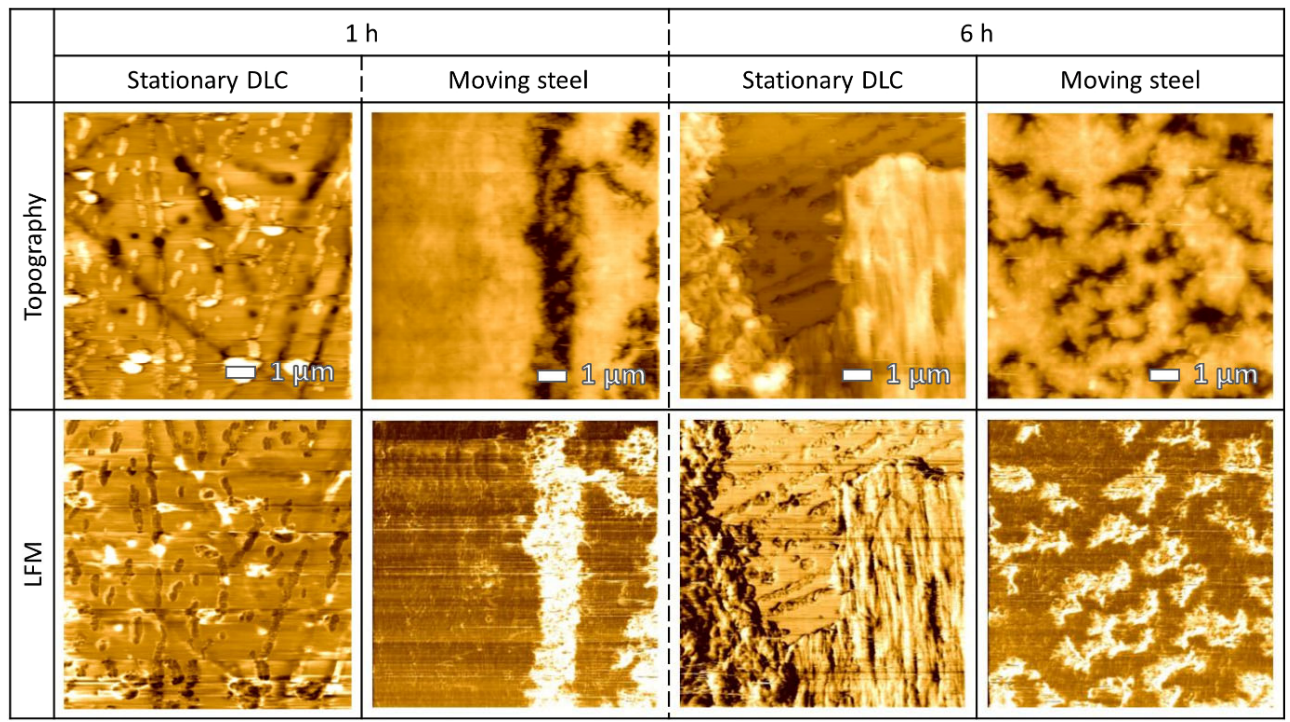

Fig. 8 Topographic and corresponding LFM images of stationary DLC and moving steel surfaces for DLC/steel contact configuration after 1-h and 6-h sliding.

almost completely covered with the film after $1 \mathrm{~h}$, and the morphology was different from that on the stationary surface. Large islands of the tribofilm disintegrated into smaller ones with longer sliding time, and the surface coverage remained practically the same.

By comparing the topographic and LFM images, it is clear that on the LFM images, the tribofilm regions on both surfaces appear darker, regardless of the sliding time, indicating that these regions have a lower nano-friction than that of the uncovered surface.
Figure 9 shows the topographic and corresponding LFM images of the stationary steel and moving DLC surfaces after 1-h and 6-h sliding. After $1 \mathrm{~h}$, the stationary steel surface was similar to both surfaces in the steel/steel contact configuration, completely covered with a tribofilm composed of multiple layers. In contrast, the film on the stationary DLC surface consisted of very thin and flat islands. The film coverage on the surface of the moving DLC surface was high, that is, approximately $88 \%$. As the sliding time increased, the film coverage remained practically 
unchanged for both contacting surfaces, measuring approximately $96 \%$ and $86 \%$ for the stationary and moving surfaces, respectively. With a longer sliding time, the films on both contacting surfaces disintegrated into smaller islands.

By comparing the topographic and LFM images of the moving DLC surface, the following observations were made: On the LFM images, the tribofilm regions appear bright, indicating that they exhibit higher nano-friction properties than the substrate. This is the opposite of the observation made for the tribofilm on the moving steel surface in the DLC/steel contact configuration, and could indicate that the film formed had a different chemical structure.

Figure 10 shows the topographic and corresponding LFM images taken on the stationary and moving DLC surfaces after 1-h and 6-h sliding.

The coverage of both contacting surfaces remained practically unchanged with an increase in the sliding time. It changed from approximately $86 \%$ to $90 \%$ and $64 \%$ to $70 \%$ for the stationary and moving DLC surfaces, respectively.

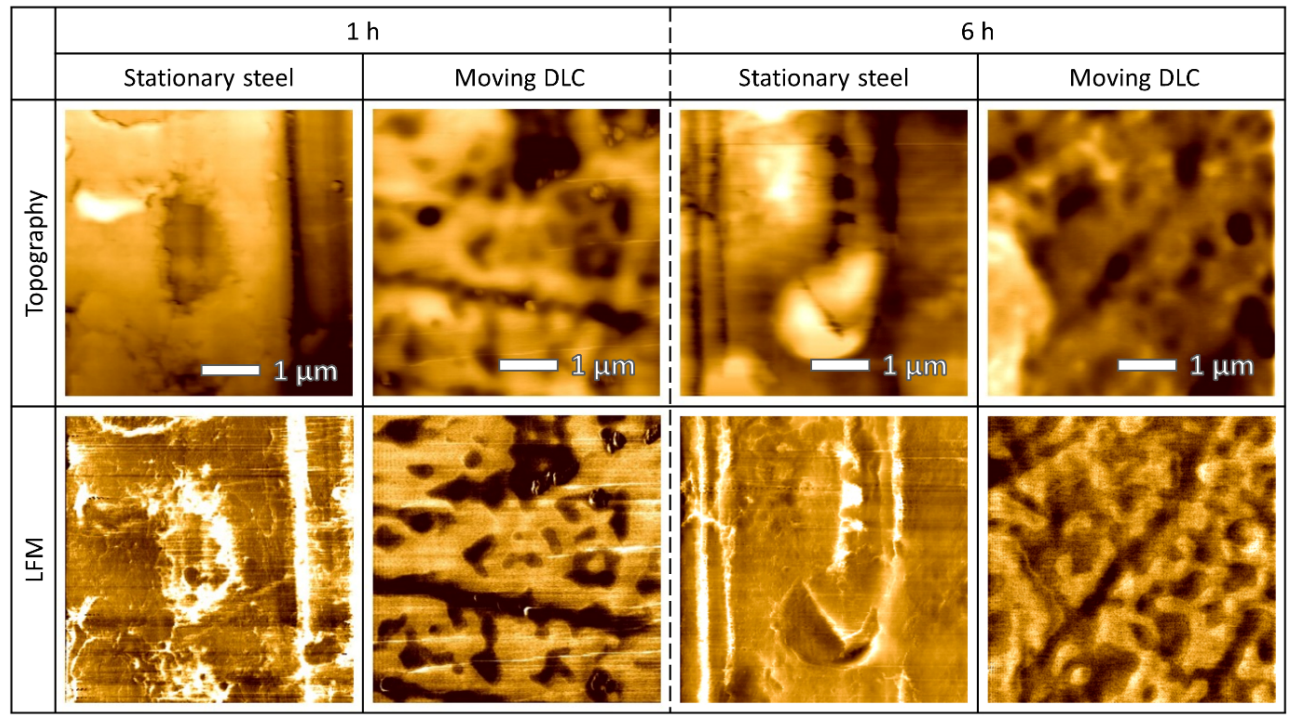

Fig. 9 Topographic and corresponding LFM images of stationary steel and moving DLC surfaces for steel/DLC contact configuration after 1-h and 6-h sliding.

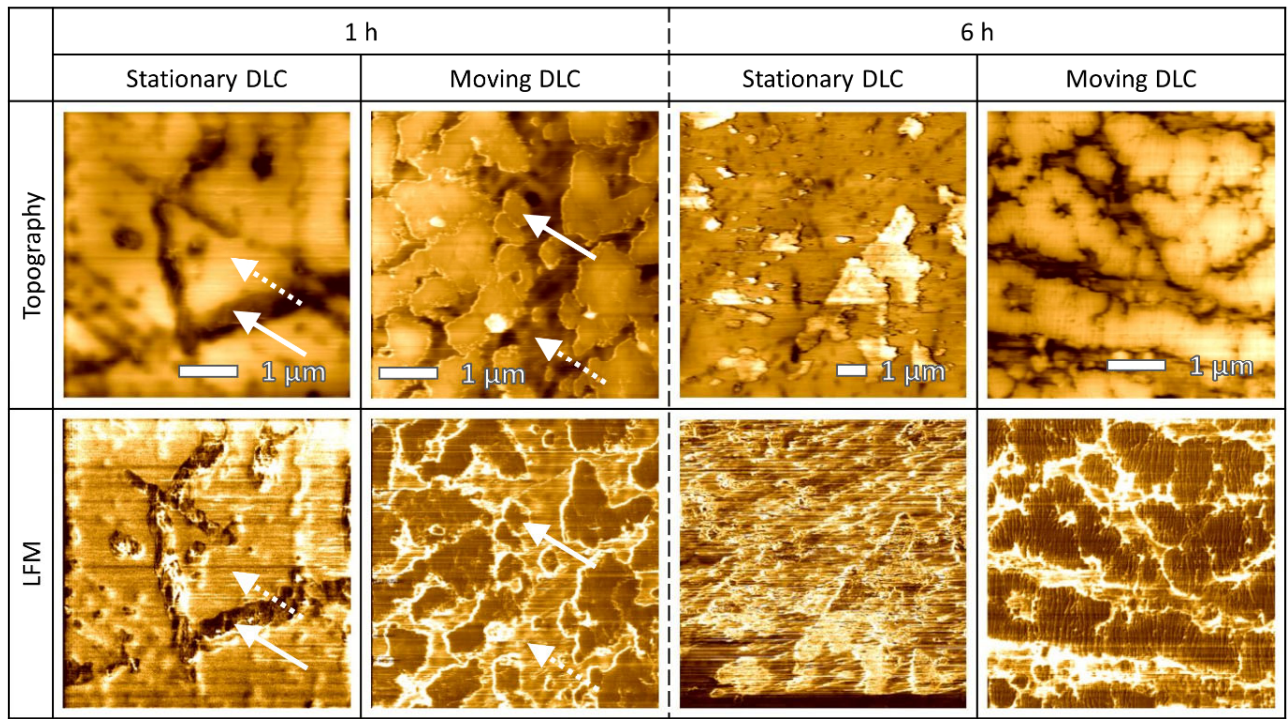

Fig. 10 Topographic and corresponding LFM images of stationary and moving DLC surfaces for DLC/DLC contact configuration after 1-h and 6-h sliding. Full and dashed arrows indicate low- and high-friction regions, respectively. 
Similar to the case of the mixed steel/DLC contact configuration, the tribofilm formed on the stationary DLC surface exhibits a brighter LFM contrast and hence, higher nano-friction than the uncovered substrate, regardless of the sliding time. In contrast, the tribofilm formed on the moving DLC surface appears darker than the regions of the uncovered substrate, indicating lower nano-friction properties of the tribofilm regions (similar to the case of the DLC/steel contact).

\subsection{Chemical structure of the tribofilm}

\subsubsection{ATR-FTIR}

Figure 11 shows the IR spectra of both contacting surfaces for all the four contact configurations after 1-h and 6-h sliding. The red dashed and full curves in the spectra correspond to the tribofilms formed on

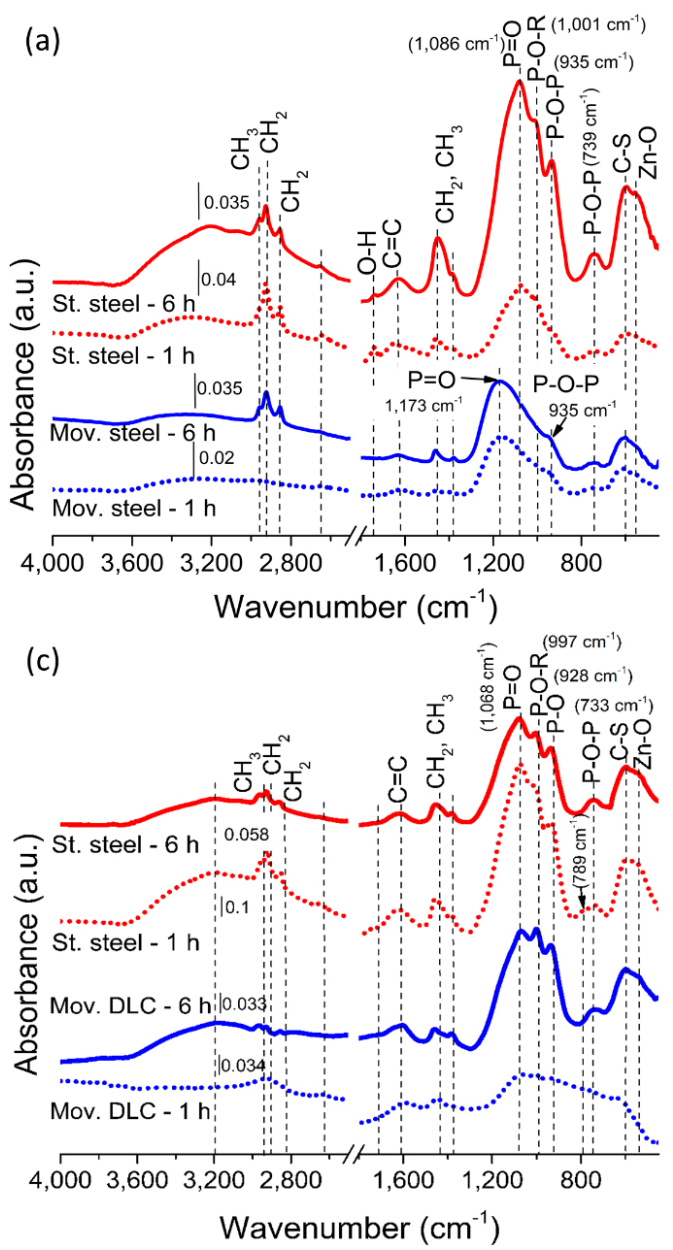

the stationary surfaces, whereas the blue dashed and full curves correspond to the tribofilms on the moving surfaces after 1-h and 6-h sliding, respectively.

For the self-mated steel/steel contact, the peaks found on the stationary steel surface after 1-h sliding corresponded to poly(organo)phosphates $\left(\left(\mathrm{PO}_{4}{ }^{2-}\right)_{n} /\right.$ $\left.\mathrm{O}=\mathrm{P}(\mathrm{OR})_{3}\right)$, alkyl sulfide $(\mathrm{C}-\mathrm{S})$, zinc oxide $(\mathrm{Zn}-\mathrm{O})$, and alkyl species $\left(\mathrm{CH}_{3} / \mathrm{CH}_{2}\right)$ (red dashed curve in Fig. 11(a)). The strong absorption bands measured in the $900-1,300 \mathrm{~cm}^{-1}$ region, with a maximum at approximately $1,100 \mathrm{~cm}^{-1}$, can be attributed to the $\mathrm{P}=\mathrm{O}$ bond of the phosphate species [33-35]. The band at $990 \mathrm{~cm}^{-1}$ is related to the asymmetric stretching of the $\mathrm{P}-\mathrm{O}-\mathrm{R}$ bond of the organophosphorus compounds, for example, $\mathrm{O}=\mathrm{P}(\mathrm{OR})_{3}[35,36]$. The two bands appearing at 935 and $740 \mathrm{~cm}^{-1}$ result from the asymmetric and symmetric stretching vibrations of the P-O-P bonds [31, 35], which could be attributed
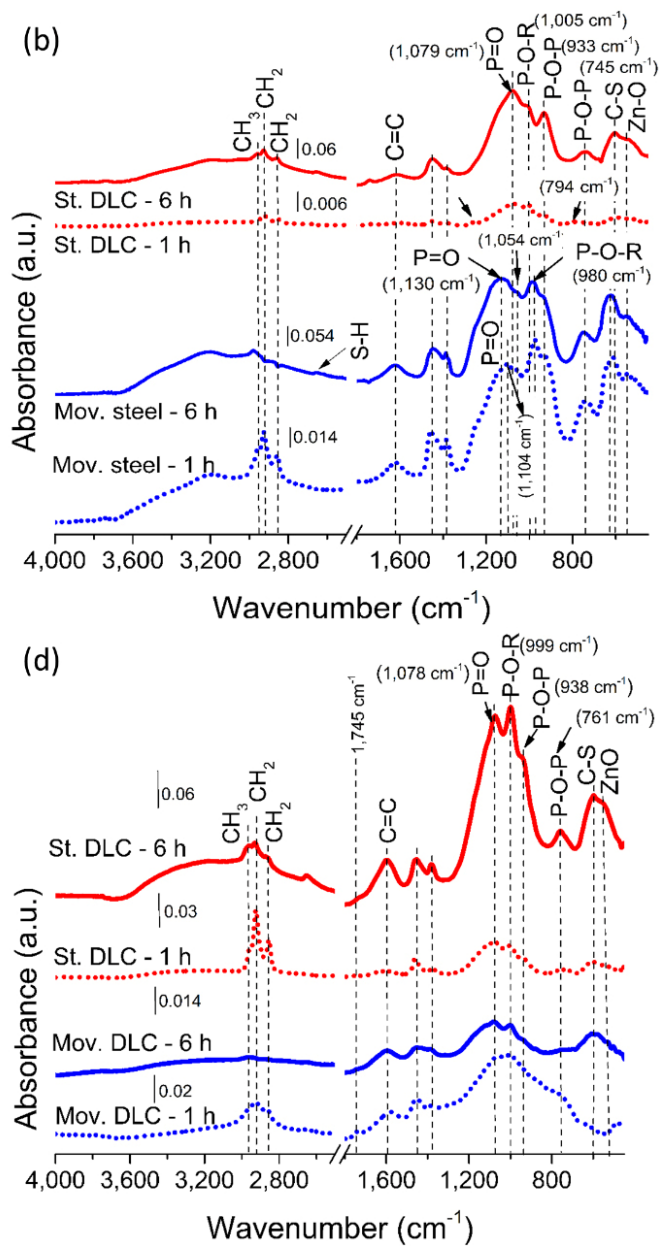

Fig. 11 IR spectra of tribofilm on stationary and moving surfaces after 1-h and 6-h sliding for (a) steel/steel, (b) DLC/steel, (c) steel/DLC, and (d) DLC/DLC contact configuration. 
to the presence of poly(organo)phosphate compounds. The band at approximately $600 \mathrm{~cm}^{-1}$ is assigned to the $\mathrm{C}-\mathrm{S}$ bond that could belong to organic sulfide compounds [35,37], whereas the band at approximately $550 \mathrm{~cm}^{-1}$ could belong to the $\mathrm{Zn}-\mathrm{O}$ bond [38-40]. The bands at 2,967, 2,923, and 2,848 $\mathrm{cm}^{-1}$ were assigned to the asymmetric stretching vibrations of $\mathrm{CH}_{3}$ and $\mathrm{CH}_{2}$, and the symmetric stretching vibration of the $\mathrm{CH}_{3}$ bonds, respectively [35, 41, 42]. The two peaks at 1,458 and $1,378 \mathrm{~cm}^{-1}$ correspond to the deformation vibrations of $\mathrm{CH}_{3} / \mathrm{CH}_{2}$, and the symmetric deformation of the $\mathrm{CH}_{3}$ bond, respectively [35, 41-43]. With prolonged sliding, all the compounds were similar, but had higher intensity (red full curve, Fig. 11(a)), indicating the growth of all the species in the tribofilm; particularly, an increase in the chain length of the poly(organo)phosphate. The chemical structure of the tribofilm on the moving steel surface differs from that on the stationary steel surface, as can be observed from the shift of the $\mathrm{P}=\mathrm{O}$ peak towards higher wavenumbers (from 1,086 to $1,173 \mathrm{~cm}^{-1}$ ) as well as the change in the peak shape [33-35] (blue dashed curve in Fig. 11(a)). Based on previous literature, the frequency of the $\mathrm{P}=\mathrm{O}$ stretching vibration is affected by the number of electronegative substituents directly bonded to it [35]. This could signify the presence of different numbers of bonded oxygen atoms in the poly(organo)phosphate structure $\left(\left(\mathrm{PO}_{4}{ }^{3-}\right)_{n+x} /\left(\mathrm{O}=\mathrm{P}(\mathrm{OR})_{3}\right)_{x}\right)$, and therefore, the presence of a different phosphate mixture. Additionally, alkyl, organic sulfide, and zinc oxide species were found on the moving steel surface. After 6-h sliding (blue full curve in Fig. 11(a)), all the species remained on the surface, but with increased intensity. This indicates the growth of all the species in the tribofilm, particularly, an increase in the alkyl and polyphosphate chain lengths.

After 1-h sliding, alkyl $\left(\mathrm{CH}_{3} / \mathrm{CH}_{2}\right)$, alkyl sulfide (C-S), zinc oxide ( $\mathrm{Zn}-\mathrm{O})$, and phosphate species were also found in the tribofilms on both contacting surfaces in the case of the DLC/steel, steel/DLC, and DLC/DLC contact configurations (compare the red and blue dashed curves in Figs. 11(a)-11(d)). However, in comparison to the steel/steel contact, significant differences in the phosphate mixtures were observed. This can be observed from the changes in the peak positions of the $\mathrm{P}=\mathrm{O}$ band to lower/higher wave- numbers (compare the red and blue dashed curves in Figs. 11(a)-11(d)), indicating that different mixtures of various types of phosphates (orthophosphate, pyrophosphate, polyphosphate, metaphosphate, and organophosphate) exist in the tribofilms formed on the different surfaces (stationary/moving) and different contact configurations. With a longer sliding time of $6 \mathrm{~h}$, all the species remained on the surfaces (red and blue dashed and full curves in Figs. 11(b)-11(d)). However, with the DLC/steel contact, similar to the steel/steel contact, the intensity of all the species on both contacting surfaces increased with the sliding time (the red and blue dashed and full curves in Fig. 11(b)). This demonstrates the growth of all the species in the tribofilm; particularly, an increase in the poly(organo)phosphate chain lengths. In contrast, in the case of the steel/DLC and DLC/DLC, the intensity of some species, that is, phosphates, on both contacting surfaces decreased (except for the stationary DLC in the DLC/DLC contact), whereas the intensity of other species, that is, the organic sulfide and zinc oxide, on both contacting surfaces increased with the sliding time (red and blue dashed and full curves in Figs. 11(c)-11(d)).

\subsubsection{XPS}

XPS analyses were performed for both contacting surfaces of the DLC/steel, steel/DLC, and DLC/DLC contacts after $1-\mathrm{h}$ and 6 -h sliding. The steel/steel contact was not presented because there are already numerous consistent and detailed analyses [44, 45]. The XPS findings confirm the presence of oxide, sulfur, phosphorous, and zinc species in the outer 5-nm tribofilms formed on the contacting surfaces of the DLC/steel, steel/DLC, and DLC/DLC contacts after 1-h and 6-h sliding, which can be observed clearly from the detailed XPS spectra of the O 1s, $S$ 2p, P 2p, and Zn 3s signals in Figs. 12-14. The XPS spectra of the $\mathrm{Zn} 2 \mathrm{p}$ signal, which was detected in the case of all the tribofilms, are not shown here. The binding energies (BEs) and intensities of all the peaks and their components are shown in Figs. 12-14. Significant differences in the full width of the XPS peaks and peak components (FWHM), and their intensities and positions (BE) between the different surfaces can be registered immediately; they show 

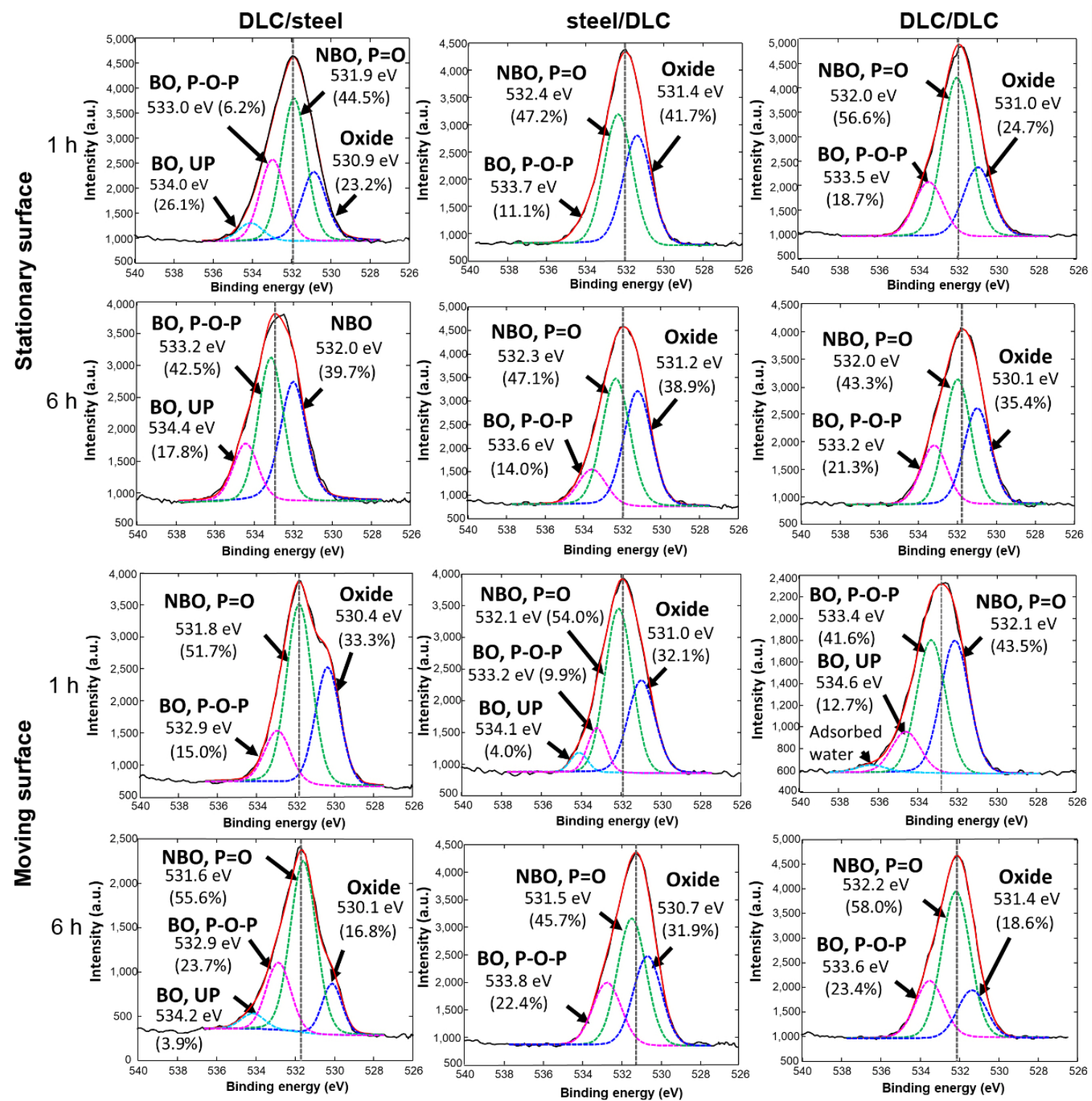

Fig. 12 XPS spectra of O 1s signal for tribofilms formed on contacting surfaces (stationary and moving) of the DLC/steel, steel/DLC, and DLC/DLC contacts after 1-h and 6-h sliding.

that the chemical composition of the outer 5-nm the tribofilm is also very different.

The $\mathrm{O} 1 \mathrm{~s}$ peak was resolved into three or four components, as shown in Fig. 12. A component at a BE of $530.0-531.4 \mathrm{eV}$ can be assigned to the oxide species (metal oxide), whereas a component at $\mathrm{BE}$ in the range of 531.5-532.6 eV can be assigned to non-bridging oxygen (NBO), participating in the $\mathrm{P}=\mathrm{O}, \mathrm{P}-\mathrm{O}-\mathrm{M}$, and $\mathrm{P}-\mathrm{O}-\mathrm{R}$ bonding. A component at $532.9-534.1 \mathrm{eV}$ is assigned to a bridging oxygen (BO), which is involved in the P-O-P bonds [44, 46, 47]. A contribution at a $\mathrm{BE}$ of 534.1-534.6 eV was observed on some surfaces, which could be assigned to a bridging oxygen as well, but in the 3D polyphosphates (ultraphosphates) [47]. The component at $536.4 \mathrm{eV}$, observed in the case of the moving DLC surface in the DLC/DLC contact after 6-h sliding, can be ascribed to partially adsorbed water [47].

The detailed XPS spectra of the S $2 p$ signal after 1-h and 6-h sliding are presented in Fig. 13. The $S 2 p$ peak was resolved into two components (one doublet) in some cases, whereas in the other cases it was resolved into four components (two doublets). For each doublet, the constant peaks' separation of $\Delta E_{\mathrm{b}}=$ 

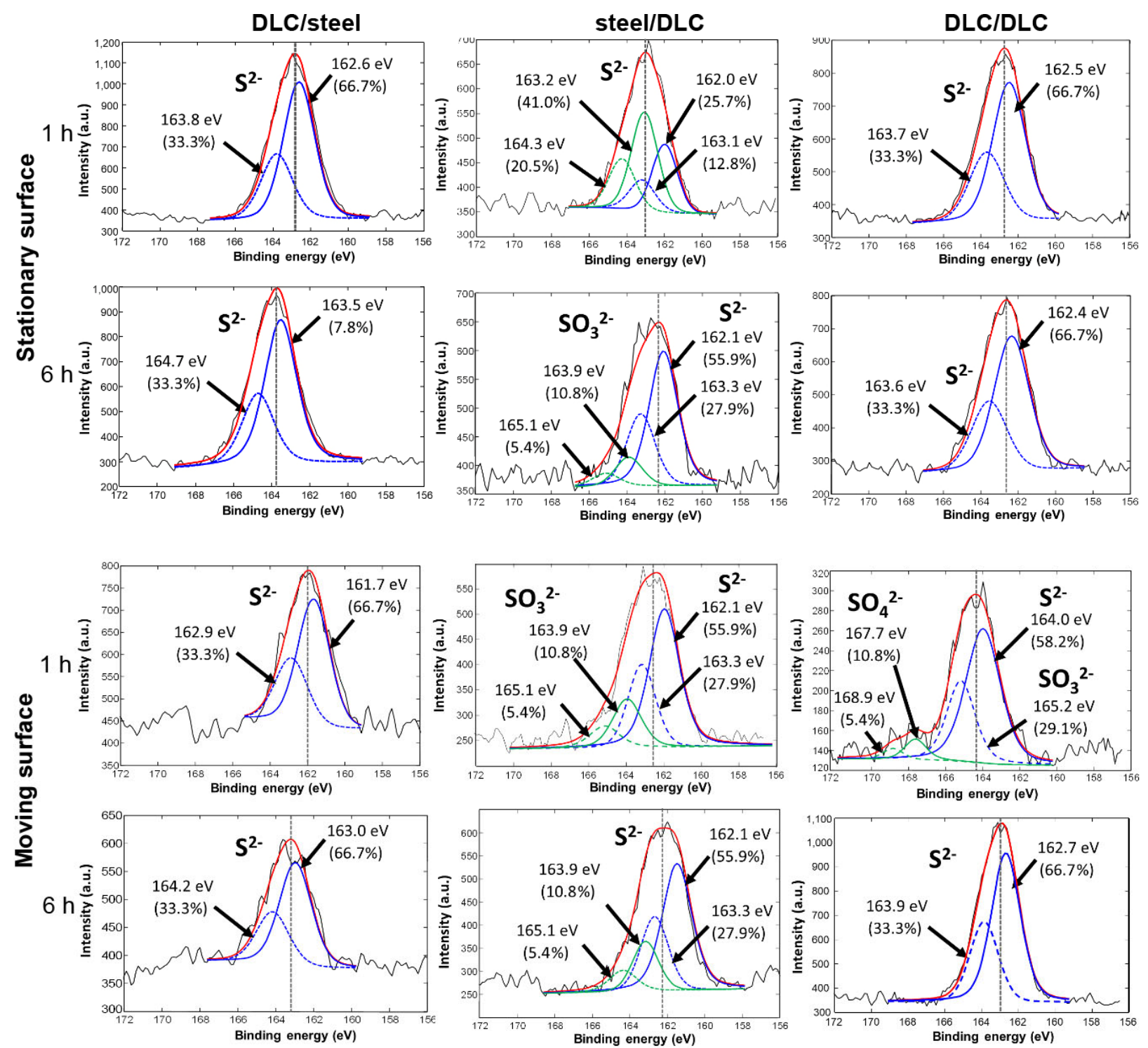

Fig. 13 XPS spectra of S $2 p$ signal for tribofilms formed on contacting surfaces (stationary and moving) of the DLC/steel, steel/DLC, and DLC/DLC contacts after 1-h and 6-h sliding.

$1.2 \mathrm{eV}$ and the constant intensity ratio of 0.5 (because of the spin-orbit coupling) were taken into account $[44,46]$. The two doublets indicate the presence of more than one chemical state. The components at BE in the range of $161.6-164.4 \mathrm{eV}$ originate from sulphide $\left(\mathrm{S}^{2-}\right)$ and organosulfur (S-R) species, which are present in all the tribofilms (Fig. 13) [44, 46, 48]. Contributions at 165.2, 167.6, and $168.8 \mathrm{eV}$, corresponding to the sulfite $\left(\mathrm{SO}_{3}{ }^{2-}\right)$ and sulfate $\left(\mathrm{SO}_{4}{ }^{2-}\right)$ species [48-50], respectively, were also observed. For example, sulfite species were found on the stationary steel surface in the steel/DLC contact after 6-h sliding, and on the DLC moving surface in the same contact, but only after 1-h sliding. Sulphite and sulfate species were observed on the moving DLC surface in the DLC/DLC contact after 1-h sliding. Only the sulfide and organosulfur species remained on the surface with a longer sliding time $(6 \mathrm{~h})$.

The P $2 p$ peak was resolved into two contributions (one doublet) or four contributions (two doublets), as shown in Fig. 14. For each doublet, the constant peak separation of $\Delta E_{\mathrm{b}}=0.85 \mathrm{eV}$ and constant intensity ratio of 0.5 were considered in the fitting procedure [44, 46]. Different peak positions and widths imply that different mixtures of various types of phosphates (orthophosphate, pyrophosphate, polyphosphate, 

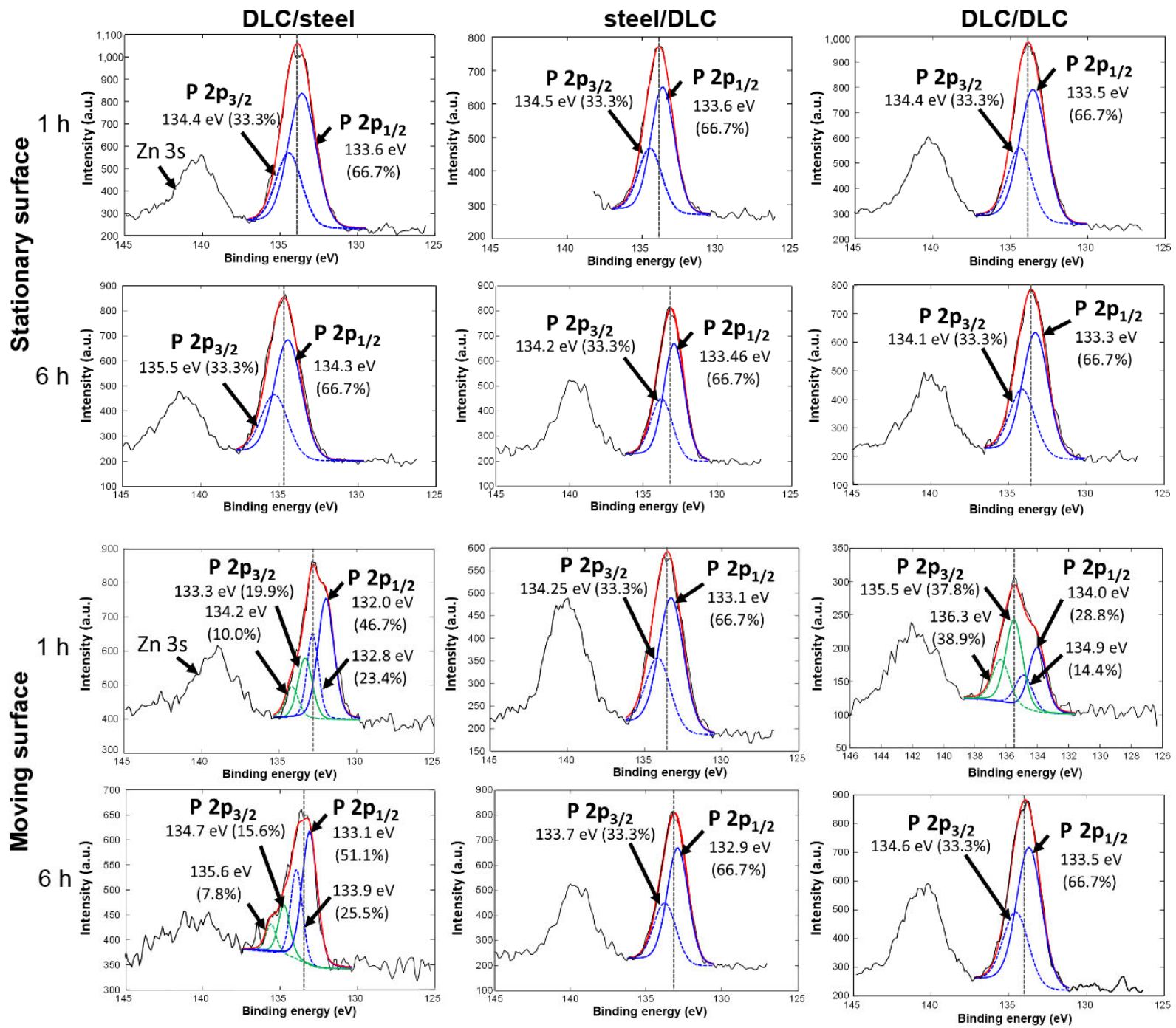

Fig. 14 XPS spectra of P 2p signal for tribofilms formed on contacting surfaces (stationary and moving) of the DLC/steel, steel/DLC, and DLC/DLC contacts after 1-h and 6-h sliding.

metaphosphates, and organophosphates) exist in the films on different surfaces, as also observed in the FTIR spectra. A change in the P $2 p$ signal toward lower/higher binding energies and changes in the full widths (FWHM) of the peaks with increasing sliding time from 1 to $6 \mathrm{~h}$ indicate that changes in the phosphate mixture occurred.

For better insight into the differences between the phosphate mixtures, the $\mathrm{BO} / \mathrm{NBO}$ areal ratio and $\mathrm{P} / \mathrm{Zn}$ intensity ratio were calculated for the evaluated surfaces (Table 2). In the case of the DLC/steel contact, a high $\mathrm{BO} / \mathrm{NBO}$ ratio of 0.73 and $\mathrm{P} / \mathrm{Zn}$ ratio of 1.2 were obtained for the stationary surface after 1-h sliding, indicating the presence of long-chain polyphosphates with a significant amount of 3D
Table $2 \mathrm{BO} / \mathrm{NBO}$ areal and $\mathrm{P} / \mathrm{Zn}$ intensity ratios for the contacting surfaces in DLC/steel, steel/DLC, and DLC/DLC contacts.

\begin{tabular}{ccccc}
\hline & Configuration & & $\mathrm{BO} / \mathrm{NBO}$ & $\mathrm{P} / \mathrm{Zn}$ \\
\hline \multirow{4}{*}{ DLC/steel } & $1 \mathrm{~h}$ & 0.73 & 1.2 \\
& \multirow{2}{*}{ Stationary DLC } & $6 \mathrm{~h}$ & 0.42 & 1.1 \\
\cline { 2 - 5 } & \multirow{2}{*}{ Moving steel } & $1 \mathrm{~h}$ & 0.29 & 0.8 \\
& & $6 \mathrm{~h}$ & 0.50 & 10.6 \\
\hline \multirow{3}{*}{ Steel/DLC } & \multirow{2}{*}{ Stationary steel } & $1 \mathrm{~h}$ & 0.23 & 1.2 \\
\cline { 2 - 5 } & \multirow{2}{*}{ Moving DLC } & $6 \mathrm{~h}$ & 0.30 & 1.1 \\
\hline \multirow{3}{*}{ DLC/DLC } & $6 \mathrm{~h}$ & 0.26 & 0.7 \\
\cline { 2 - 5 } & \multirow{2}{*}{ Stationary DLC } & $1 \mathrm{~h}$ & 0.49 & 0.8 \\
\cline { 2 - 5 } & \multirow{2}{*}{ Moving DLC } & $6 \mathrm{~h}$ & 0.49 & 1.1 \\
& & $6 \mathrm{~h}$ & 1.24 & 2.1 \\
\hline
\end{tabular}


polyphosphate (ultra-phosphate) [44, 47, 51]. With an increase in the sliding time to $6 \mathrm{~h}$, the $\mathrm{BO} / \mathrm{NBO}$ ratio decreased to approximately 0.42 , whereas the $\mathrm{P} / \mathrm{Zn}$ ratio remained relatively the same. This signifies the presence of long-chain polyphosphates only. For the moving steel surface of the same contact, the $\mathrm{BO} / \mathrm{NBO}$ value of 0.29 after 1 -h sliding increased to 0.5 after 6 -h sliding, indicating a transition from a mixture of pyrophosphate and short-chain polyphosphates to a mixture of very long polyphosphates and a small amount of ultra-phosphates [44, 47, 51]. The presence of very long-chain polyphosphates is supported by the very high $\mathrm{P} / \mathrm{Zn}$ ratio (10.6). In the case of steel/DLC on both contacting surfaces, pyrophosphates and short-chain polyphosphates were detected after 1-h sliding. With longer sliding time, the $\mathrm{BO} / \mathrm{NBO}$ ratio increased to 0.30 and 0.49 for the stationary and moving surfaces, respectively. The $\mathrm{P} / \mathrm{Zn}$ ratio remained unchanged for both surfaces. These changes indicate a slight increase in the polyphosphate chain length.

In the DLC/DLC contact, the $\mathrm{BO} / \mathrm{NBO}$ ratio for the stationary DLC surface increased from 0.33 after 1 -h sliding to 0.49 after 6 -h sliding, which may indicate a small amount of an ultra-phosphate within the tribofilm. A slight decrease in the $\mathrm{P} / \mathrm{Zn}$ ratio from 1.1 to 0.8 could imply a slight decrease in the polyphosphate chain length. For the moving DLC surface, a $\mathrm{BO} / \mathrm{NBO}$ ratio of 1.24 , and $\mathrm{P} / \mathrm{Zn}$ ratio of 2.1 were obtained. After a longer sliding time, both the $\mathrm{BO} / \mathrm{NBO}$ and $\mathrm{P} / \mathrm{Zn}$ ratios decreased significantly (to 0.40 and 1.0, respectively), indicating that a mixture of very long polyphosphates and a large amount of ultra-phosphate changed to a mixed structure of short-chain and long-chain polyphosphates.

\section{Discussion}

The type of material in the contact (steel or DLC) and the contact configuration (moving/stationary) were shown to influence tribofilm growth; these result in different friction properties for the evaluated contacts. To understand the effect of ZDDP on the friction behavior of the evaluated contacts, three properties of the formed tribofilms were analyzed: thickness, morphology, and chemical structure.
The correlation between the film properties and $\mathrm{COF}$ is more relevant after 6-h sliding when the films become steadier. We observed that after 6-h sliding, the total film thickness was the lowest in the DLC/DLC contact, followed by the steel/DLC, and DLC/steel, whereas the greatest thickness was measured for the steel/steel contact (Figs. 4(b) and 15). The variations in the film thickness could be attributed to the different adhesion abilities of the moving body and forming film, which are very important when film shear is introduced by pulling the moving body. It is known that DLC exhibits a lower limiting shear stress owing to lower adsorption, and does not sustain the same high shear rates in comparison to the better adhesion of the films with the steel [52, 53]. When the moving body is DLC, the tribofilm thickness on the DLC is lower, and consequently, the total tribofilm thickness is lower. Similar phenomena were recently observed for the boundary slip of DLC and oil because of poor wetting [54], which in EHL, enhances the boundary slip. However, when the moving body is steel, the film thickness on the steel is greater, and subsequently, the tribofilm is thicker. However, it should be noted that a combination of the moving body (steel or DLC) with more reactive stationary steel results in a higher total thickness than with stationary DLC.

The low total tribofilm thickness resulted in lower friction, whereas the higher thickness resulted in higher friction, as shown in Figs. 3(b), 4(b), and 15, and reported in Ref. [10]. This is notable in the case of the self-mated contacts, steel/steel, and DLC/DLC, which exhibit the highest and lowest COFs, respectively. In contrast, the influence of the film thickness on the friction behavior of the mixed contacts is unclear and can be explained as follows. In steel/DLC contacts, a low tribofilm thickness on the moving DLC surface results in a larger number of contacts between the bare surface asperities (steel and much harder DLC), which in turn causes higher friction. In contrast, in the DLC/steel contact, a higher tribofilm thickness on the stationary DLC results in a smaller number of contacts between the bare surface asperities, causing lower friction. The lowest friction observed in the case of the DLC/DLC contact is attributed to the very low film thickness on both contacting surfaces, which causes the intrinsic low-friction properties of the bare DLC surfaces to prevail. 
Measuring the tribofilm thickness after different sliding time ( 1 and $6 \mathrm{~h}$ ) reveals that the total tribofilm thickness increases when in contact with steel as a moving body, and decreases when in contact with DLC as a moving body with increasing sliding time (Fig. 4). Consequently, changes in the tribofilm thickness influence the friction behavior of the contacts, particularly, in the self-mated ones. Here, an increase in the thickness leads to a higher $\mathrm{COF}$ and vice versa (Figs. 3 and 4). In the mixed contacts, the influence of the changes in the tribofilm thickness with time on the COF is unclear. In the DLC/steel contact, only a minor increase in the COF was observed (by approximately $2 \%$ ), whereas in the steel/DLC contact, an increase of approximately $20 \%$ was obtained, even though the tribofilm thickness decreased. The latter could be attributed to the increased number of contacts between the asperities of the bare DLC and steel surfaces.

The thickness and morphology of the tribofilms are closely related, and their effects on friction are difficult to differentiate; however, the effects of both are more pronounced after longer sliding time. The films on all the steel surfaces disintegrated into smaller pads with longer sliding time (Figs. 7, 8, 9, and 15), which, according to the previous research on ZDDP $[4,18,19]$, could contribute to higher friction in the steel/steel, DLC/steel, and steel/DLC contacts owing to an increase in the surface roughness. However, film disintegration on the DLC surfaces in the case of the steel/DLC and DLC/DLC contacts contributes to an increased number of contacts between the bare surfaces, which leads to an increase in the COF in the steel/DLC contact, and a decrease in the COF in the DLC/DLC contact.

The chemical structure of all the tribofilms consists of alkyl $\left(\mathrm{CH}_{3} / \mathrm{CH}_{2}\right), \mathrm{ZnO}$, organosulfur, and poly(organo)phosphate species (Fig. 11), regardless of the contact configuration. Although their general composition is similar, there is a significant variation in the presence of dissimilar mixtures of various types of phosphates in the films formed on different surfaces, particularly in their lengths (orthophosphate, pyrophosphate, polyphosphate, and metaphosphate). This can be observed from the variations in the intensities and positions of the IR peaks as well as the variations in the $\mathrm{BO} / \mathrm{NBO}$ and $\mathrm{P} / \mathrm{Zn}$ ratios in the outer 5-nm film (Figs. 11, 12, 14, and Table 2). However, from all these variations, it is impossible to find a clear explanation, contact conditions, and contact configuration (moving body/materials) that will result in a specific structure of the tribofilm. It should also be mentioned that the film structure in comparison to the film thickness does not have a direct influence on the friction behavior of the contacts. According to publications by others, short-chain polyphosphates usually result in a lower COF compared to longer-chain ones [55]. In our case, this is true for the DLC/ DLC contact, where the lowest friction coincides with the presence of short and short-tomiddle chain-length polyphosphates detected on the stationary and moving surfaces, respectively (Table 2). However, this does not apply to the DLC/steel and steel/DLC contacts. In the first case, the presence of long and very long phosphates on the stationary and moving surfaces, respectively, resulted in the secondlowest COF, whereas in the latter case, the presence of the short-to-middle chain-length polyphosphates on both contacting surfaces led to a $25 \%$ higher COF than in the DLC/steel contact. This shows that the film structure contributes to the increase/decrease of the COF by only a smaller extent.

Further, some consistencies between the changes in the film structure and thickness were observed. One of them is the intensity of the phosphate IR peak, which increased in the contacts with steel as the moving body (steel/steel, DLC/steel) and decreased in those with DLC as the moving body (steel/DLC, DLC/DLC) as the films become more stable. The increase in the phosphate intensity is in good agreement with the increase in the tribofilm thickness with sliding time and vice versa (Figs. 4, 11(a), and 11(b)). Overall, significant differences were observed depending on the contact configuration. In some cases, a clear explanation can be given, often consistent with past studies and understanding of well-known theories or effects, especially for the self-mated steel/steel or DLC/DLC contacts. However, in some cases, no clear explanation is given, most probably because of the simultaneous effects of the surface features and contact configuration. It is clear that any prediction of the behavior and understanding of the fundamentals remains limited especially for mixed steel-DLC contacts. 


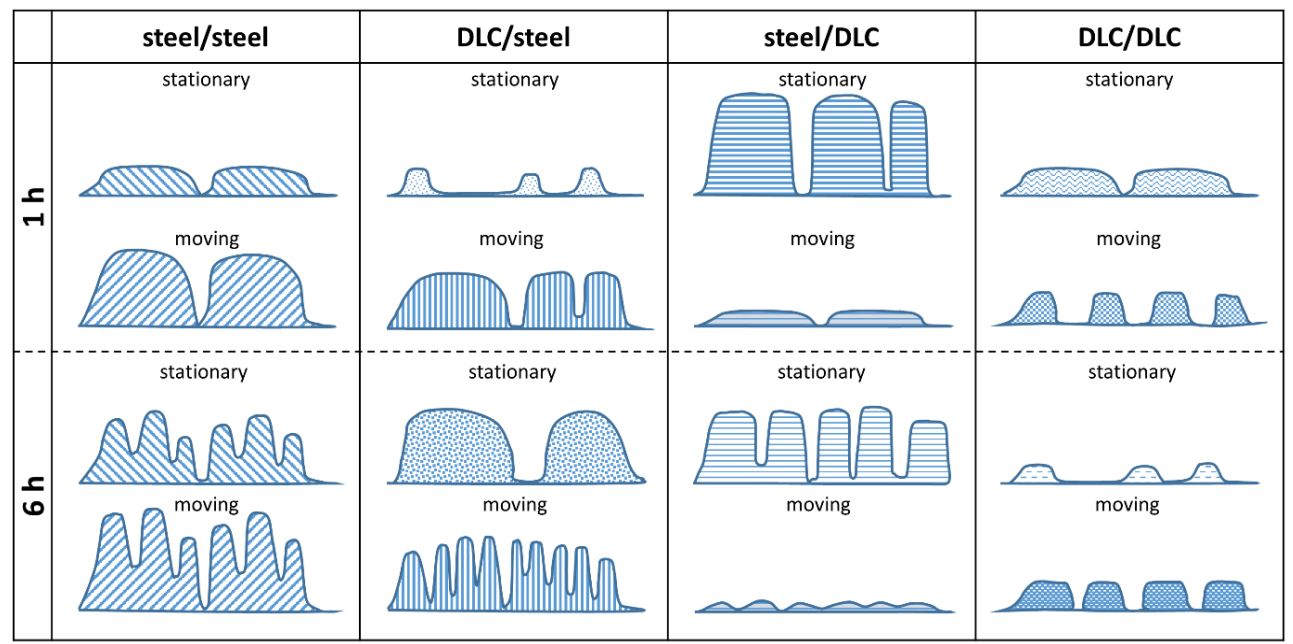

Fig. 15 Schematics of ZDDP tribofilm formation on all contacting surfaces for all contact configurations.

\section{Conclusions}

1) The formation of a tribofilm significantly depends on the surface reactivity of the material, as well as the contact configuration, which clearly influenced all the evaluated parameters.

2) The thickness of the tribofilm can vary from approximately 60 to $330 \mathrm{~nm}$. The thickness is higher on the steel surfaces than on the DLC surfaces. In mixed DLC-steel contacts, the thickness is higher on the stationary steel surface than on the moving steel surface.

3) Thicker films result in higher friction in the selfmated contacts; thus, friction is higher on steel/steel than on DLC/DLC. Mixed contacts do not reveal a clear conclusion in terms of the thickness-friction property, probably because of other effects such as morphology and chemistry.

4) The morphology of a tribofilm exhibits different features, that is, adhered islands that can be high or low, large or small areas of coverage, and additives adhering fully or partially covering the surface. With time, the area of the islands decreases (they disintegrate), which has a different effect on the friction in the mixed contacts, but clearly reduces the friction in the DLC/DLC contacts.

5) Nano-friction, similar to macro-friction, is significantly affected by the tribofilm's characteristics, which depend on the configuration of the contact.

6) All the contact configurations consist of alkyl $\left(\mathrm{CH}_{3} /\right.$ $\left.\mathrm{CH}_{2}\right), \mathrm{ZnO}$, organosulfur, and poly(organo)phosphate species; however, they possess dissimilar mixtures of various types of phosphates, particularly related to their lengths (orthophosphate, pyrophosphate, polyphosphate, and metaphosphate), as well as variations in the ratios of the bridging oxygen (BO)/non-bridging oxygen $(\mathrm{NBO})$ and $\mathrm{P} / \mathrm{Zn}$ at the outer $5 \mathrm{~nm}$ of the film.

7) Steel/steel and DLC/DLC contacts have more predictable behavior and follow known theories and effects for film formation, whereas mixed steel-DLC contacts are relatively unpredictable, which means that we do not understand their tribofilm properties; therefore, our knowledge on their tribological behavior remains limited.

\section{Acknowledgements}

The authors acknowledge the financial support from the Slovenian Research Agency ARRS (research core funding No. P2-0231 Tribology and research project No. J2-7115 Nanoscale engineering of the contact interfaces for green lubrication technology). The authors also acknowledge F. Meunier from Oerlikon Balzers for providing the DLC coatings used in this work.

Open Access This article is licensed under a Creative Commons Attribution 4.0 International License, which permits use, sharing, adaptation, distribution and reproduction in any medium or format, as long as you give appropriate credit to the original author(s) and the source, provide a link to the Creative Commons licence, and indicate if changes were made. 
The images or other third party material in this article are included in the article's Creative Commons licence, unless indicated otherwise in a credit line to the material. If material is not included in the article's Creative Commons licence and your intended use is not permitted by statutory regulation or exceeds the permitted use, you will need to obtain permission directly from the copyright holder.

To view a copy of this licence, visit http://creativecommons.org/licenses/by/4.0/.

\section{References}

[1] Donnet C, Erdemir A. Tribology of Diamond-like Carbon Films: Fundamentals and Applications. New York (US): Springer Verlag, 2008.

[2] Grill A. Diamond-like carbon: State of the art. Diam Relat Mater 8(2-5): 428-434 (1999)

[3] Haque T, Morina A, Neville A, Kapadia R, Arrowsmith S. Effect of oil additives on the durability of hydrogenated DLC coating under boundary lubrication conditions. Wear 266(1-2): 147-157 (2009)

[4] Spikes H. The History and Mechanisms of ZDDP. Tribol Lett 17: 469-489 (2004)

[5] Vengudusamy B, Green J H, Lamb G D, Spikes H A. Tribological properties of tribofilms formed from ZDDP in DLC/DLC and DLC/steel contacts. Tribol Int 44: 165-174 (2011)

[6] Topolovec-Miklozic K, Lockwood F, Spikes H. Behaviour of boundary lubricating additives on DLC coatings. Wear 265(11-12): 1893-1901 (2008)

[7] Equey S, Roos S, Mueller U, Hauert R, Spencer N D, Crockett $\mathrm{R}$. Tribofilm formation from $\mathrm{ZnDTP}$ on diamond-like carbon. Wear 264(3-4): 316-321 (2008)

[8] Haque T, Morina A, Neville A, Kapadia R, Arrowsmith S. Study of the ZDDP antiwear tribofilm formed on the DLC coating using AFM and XPS techniques. In Automotive lubricant testing and advanced additive development, West Conshohocken, Pennsylvania: ASTM Int, 2007: 92-102.

[9] de Barros'Bouchet M I, Martin J M, Le-Mogne T, Vacher B. Boundary lubrication mechanisms of carbon coatings by MoDTC and ZDDP additives. Tribol Int 38(3): 257-264 (2005)

[10] Kalin M, Oblak E, Akbari S. Evolution of the nano-scale mechanical properties of tribofilms formed from low- and high-SAPS oils and ZDDP on DLC coatings and steel. Tribol Int 96: 43-56 (2016)

[11] Vengudusamy B, Green J H, Lamb G D, Spikes H A. Influence of hydrogen and tungsten concentration on the tribological properties of DLC/DLC contacts with ZDDP. Wear 298-299: 109-119 (2013)

[12] Kano M, Yasuda Y, Ye J P. The effect of ZDDP and MoDTC additives in engine oil on the friction properties of DLCcoated and steel cam followers. Lubr Sci 17: 95-103 (2004)

[13] Spikes H A. Beyond ZDDP. Lubr Sci 20: 77-78 (2008)

[14] Martin J M, Grossiord C, Le Mogne T, Bec S, Tonck A. The two-layer structure of ZnDTP tribofilms: Part I: AES, XPS and XANES analyses. Tribol Int 34(8): 523-530 (2001)

[15] Aktary M, McDermott M T, McAlpine G A. Morphology and nanomechanical properties of ZDDP antiwear films as a function of tribological contact time. Tribol Lett 12(3): 155-162 (2002)

[16] Nicholls M A, Do T, Norton P R, Bancroft G M, Kasrai M, Capehart T W, Cheng Y T, Perry T. Chemical and mechanical properties of ZDDP antiwear films on steel and thermal spray coatings studied by XANES spectroscopy and nanoindentation techniques. Tribol Lett 15(3): 241-248 (2003)

[17] Nicholls M A, Do T, Norton P R, Kasrai M, Michael Bancroft G. Review of the lubrication of metallic surfaces by zinc dialkyl-dithiophosphates. Tribol Int 38(1): 15-39 (2005)

[18] Bennett P A. A Surface effect associated with the use of oils containing zinc dialkyl dithiophosphate. ASLE Trans 2: 78-90 (1959)

[19] Taylor L J, Spikes H A. Friction-enhancing properties of ZDDP antiwear additive: Part I-Friction and morphology of ZDDP reaction films. Tribol Trans 46(3): 303-309 (2003)

[20] Haque T, Morina A, Neville A, Kapadia R, Arrowsmith S. Non-ferrous coating/lubricant interactions in tribological contacts: Assessment of tribofilms. Tribol Int 40(10-12 SPEC. ISS.): 1603-1612 (2007)

[21] Kalin M, Vižintin J, Barriga J, Vercammen K, Acker K V, Arnšek A. The effect of doping elements and oil additives on the tribological performance of boundary-lubricated DLC/DLC contacts. Tribol Lett 17(4): 679-688 (2004)

[22] Kalin M, Roman E, Ožbolt L, Vižintin J. Metal-doped (Ti, WC) diamond-like-carbon coatings: Reactions with extremepressure oil additives under tribological and static conditions. Thin Solid Films 518(15): 4336-4344 (2010)

[23] Ban M, Ryoji M, Fujii S, Fujioka J. Tribological characteristics of Si-containing diamond-like carbon films under oillubrication. Wear 253(3-4): 331-338 (2002)

[24] Oblak E, Kalin M. Relationship between the nanoscale topographical and mechanical properties of tribochemical films on DLC coatings and their macroscopic friction behavior. Tribol Lett 59(3): 1-16 (2015)

[25] Haque T, Morina A, Neville A. Influence of friction modifier and antiwear additives on the tribological performance of a non-hydrogenated DLC coating. Surf Coat Technol 204(24): 4001-4011 (2010) 
[26] Kalin M, Vižintin J. Differences in the tribological mechanisms when using non-doped, metal-doped (Ti, WC), and non-metaldoped $(\mathrm{Si})$ diamond-like carbon against steel under boundary lubrication, with and without oil additives. Thin Solid Films 515(4): 2734-2747 (2006)

[27] Pogačnik A, Kupec A, Kalin M. Tribological properties of polyamide (PA6) in self-mated contacts and against steel as a stationary and moving body. Wear 378-379: 17-26 (2017)

[28] Vengudusamy B, Green J H, Lamb G D, Spikes H A. Durability of ZDDP tribofilms formed in DLC/DLC contacts. Tribol Lett 51(3): 469-478 (2013)

[29] Kalin M, Roman E, Vižintin J. The effect of temperature on the tribological mechanisms and reactivity of hydrogenated, amorphous diamond-like carbon coatings under oil-lubricated conditions. Thin Solid Films 515(7-8): 3644-3652 (2007)

[30] Tasdemir H A, Wakayama M, Tokoroyama T, Kousaka H, Umehara N, Mabuchi Y, Higuchi T. Ultra-low friction of tetrahedral amorphous diamond-like carbon (ta-C DLC) under boundary lubrication in poly alpha-olefin (PAO) with additives. Tribol Int 65: 286-294 (2013)

[31] Akbari S, Kovač J, Kalin M. Effect of ZDDP concentration on the thermal film formation on steel, hydrogenated nondoped and Si-doped DLC. Appl Surf Sci 383: 191-199 (2016)

[32] Topolovec-Miklozic K, Forbus T R, Spikes H A. Film thickness and roughness of ZDDP antiwear films. Tribol Lett 26(2): 161-171 (2007)

[33] Rossi A, Eglin M, Piras F M, Matsumoto K, Spencer N D. Surface analytical studies of surface-additive interactions, by means of in situ and combinatorial approaches. Wear 256(6): 578-584 (2004)

[34] Du J, Jiao L, Wu Q, Liu Y, Zhao Y, Guo L, Wang Y, Yuan H. Synthesis and characterization of $\mathrm{Li}_{2} \mathrm{FeP}_{2} \mathrm{O}_{7} / \mathrm{C}$ nanocomposites as cathode materials for Li-ion batteries. Electrochim Acta 103: 219-225 (2013)

[35] George S. Infrared and Raman Characteristic Group Frequencies. New York: John Wiley \& Sons Ltd., 2001.

[36] McIvor R A, Hubley C E. Infrared spectra of organophosphorus compounds: iii. Phosphoramidates, phosphoramidothionates, and related compounds. Can J Chem 37: 869-876 (1959)

[37] Mochizuki Y, Sugawara K. Selective separation of thiols from a model fuel by metal oxides. Energy Fuels 22(6): 3939-3943 (2008)

[38] Salavati-Niasari M, Davar F, Khansari A. Nanosphericals and nanobundles of $\mathrm{ZnO}$ : Synthesis and characterization. $J$ Alloys Compd 509(1): 61-65 (2011)

[39] Li B J, Cao H Q. ZnO@graphene composite with enhanced performance for the removal of dye from water. $J$ Mater Chem 21(10): 3346-3349 (2011)

[40] Pung S Y, Choy K L, Vinogradov E A, Novikova N N,
Yakovlev V A. Structural and infrared properties of zinc oxide film and nanowires. J Cryst Growth 312(15): 2220-2225 (2010)

[41] Mangolini F, Rossi A, Spencer N D. Chemical reactivity of triphenyl phosphorothionate (TPPT) with iron: An ATR/ FT-IR and XPS investigation. $J$ Phys Chem $C$ 115(4): 1339-1354 (2011)

[42] Mangolini F, Rossi A, Spencer N D. In situ attenuated total reflection (ATR/FT-IR) tribometry: A powerful tool for investigating tribochemistry at the lubricant-substrate interface. Tribol Lett 45(1): 207-218 (2012)

[43] Singh A, Gandra R T, Schneider E W, Biswas S K. Studies on the aging characteristics of base oil with amine based antioxidant in steel-on-steel lubricated sliding. $J$ Phys Chem C 117(4): 1735-1747 (2013)

[44] Heuberger R, Rossi A, Spencer N D. XPS study of the influence of temperature on ZnDTP tribofilm composition. Tribol Lett 25(3): 185-196 (2007)

[45] Piras F M, Rossi A, Spencer N D. Combined in situ (ATR FT-IR) and ex situ (XPS) study of the ZnDTP-Iron surface interaction. Tribol Lett 15(3): 181-191 (2003)

[46] Eglin M, Rossi A, Spencer N D. X-ray photoelectron spectroscopy analysis of tribostressed samples in the presence of ZnDTP: A combinatorial approach. Tribol Lett 15(3): 199-209 (2003)

[47] Zhou J G, Thompson J, Cutler J, Blyth R, Kasrai M, Bancroft G M, Yamaguchi E. Resolving the chemical variation of phosphates in thin ZDDP tribofilms by X-ray photoelectron spectroscopy using synchrotron radiation: Evidence for ultraphosphates and organic phosphates. Tribol Lett 39(1): 101-107 (2010)

[48] Moulder J F, Stickle W F, Sobol P E, Bomben K D. Handbook of X-ray Photelectron Spectroscopy. Minnesota (USA): Perkin-Elmer Corporation, 1992.

[49] Konno H, Sasaki K, Tsunekawa M, Takamori T, Furuichi R. X-Ray photoelectron spectroscopic analysis of surface products on pyrite formed by bacterial leaching. Bunseki Kagaku 40(11): 609-616 (1991) (in Japanese)

[50] Matsumoto K. Surface chemical and tribological investigations of phosphorus-containing lubricant additives. Ph.D. Thesis. Zürich (Switzerland): ETH Zürich, 2003.

[51] Crobu M, Rossi A, Mangolini F, Spencer N D. Chainlength-identification strategy in zinc polyphosphate glasses by means of XPS and ToF-SIMS. Anal Bioanal Chem 403(5): 1415-1432 (2012)

[52] Erdemir A, Eryilmaz O L, Nilufer I B, Fenske G R. Synthesis of superlow-friction carbon films from highly hydrogenated methane plasmas. Surf Coat Tech 133-134: 448-454 (2000)

[53] Fontaine J, Donnet C, Grill A, LeMogne T. Tribochemistry between hydrogen and diamond-like carbon films. Surf Coat 
Tech 146-147: 286-291 (2001)

[54] Polajnar M, Kalin M. Effect of the slide-to-roll ratio and the contact kinematics on the elastohydrodynamic friction in diamond-like-carbon contacts with different wetting

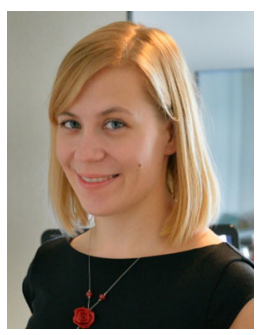

Lucija ČOGA. She received her bachelor degree in chemistry from University of Ljubljana, Slovenia, in 2011 and her Ph.D. degree in physics in 2015 from University of Ljubljana. During her Ph.D. study, she was working as a young researcher at the Faculty of Mathematics and Physics in the research area of self-assembly of lipophilic

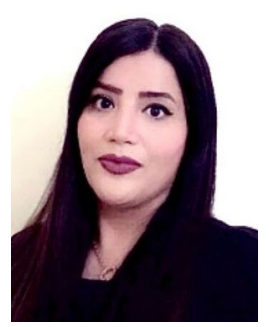

Somayeh AKBARI. She received her bachelor degree in physical chemistry from Tarbiat Moallem University, Iran, in 2010. After that, she studied nanoscience at the Universidad del País Vasco, Spain, from where she received her Master degree in 2012. In 2012, she received Marie Curie

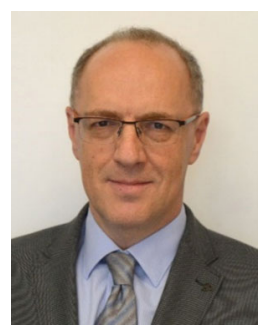

Janez KOVAČ. He received his Ph.D. degree in electronic vacuum technologies at the University of Maribor, Slovenia, in 2000. From 1991 to 1996, he was a researcher at the synchrotron light source Elettra in Trieste, Italy. From 1996 to 2003, he was a researcher at the Institute of Surface Engineering and Optoelectronics, and from 2003 to 2019, he is a

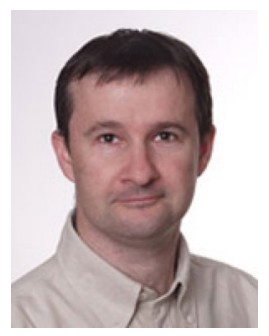

Mitjan KALIN. He received his Ph.D. degree from Faculty of Mechanical Engineering at University of Ljubljana, Slovenia, in 1999. After his post-doc research at National Institute of Standards and Technology (NIST, Gaithersburg, USA), he joined the University of Ljubljana in 2000 as an assistant professor, where he is now a full professor, behaviours. Tribol Lett 60(1): 1-10 (2015)

[55] Crobu M, Rossi A, Spencer N D. Effect of chain-length and countersurface on the tribochemistry of bulk zinc polyphosphate glasses. Tribol Lett 48(3): 393-406 (2012)

nucleoside derivatives in thin surface films. Since 2016, she has been working in the Laboratory for Tribology and Interface Nanotechnology at the Faculty of Mechanical engineering in Ljubljana. Her research areas cover nanoscale interface phenomena, boundary films, and novel green-lubrication technologies. She specialized in characterization of surface films at nanoscale using different scanning probe microscopies, electron microscopy, and neutron reflectometry.

scholarship and joined the Laboratory for Tribology and Interface Nanotechnology as a Ph.D. student under the mentorship of Professor Mitjan Kalin. She finished her Ph.D. degree in 2016. During her Ph.D. study, she was working on reaction mechanisms of ZDDP additives in thermal films and tribofilms. Currently, she is employed as CEO of the NanoSciTech Company in Munich, Germany.

Senior Research Associate at Jozef Stefan Institute, Ljubljana, Slovenia. He is currently a head of the Laboratory for Surface and Thin Film Analyses at Jozef Stefan Institute. In the period of 2013-2019, he was the president of the Slovenian Vacuum Society. The main fields of scientific interest of Janez Kovač are reactions at solid surfaces, thin films and multilayer structures, plasma physics, high resolution XPS, SIMS and AES depth profiling, and vacuum science and technology.

head of the Laboratory for Tribology and Interface Nanotechnology, and head of the Chair for Tribology and Maintenance Technology. Currently he holds a position of a dean of the Faculty of Mechanical Engineering in a four-year term. His research areas cover the wear and friction mechanisms of advanced materials, nanoscale interface phenomena, and boundary films and contact engineering for novel green-lubrication technologies. 